\title{
RELACIONES FENOTIPÍCAS Y GENÉTICAS ENTRE RAZAS TARDÍAS DE MAÍZ (ZEA MAYS SSP. MAYS) NATIVAS DE LA PROVINCIA DE Misiones (ARgENTINA)
}

\author{
Phenetic And genetic Relationships among LATE LANDRACES Of MAize \\ (ZEA MAYS SSP. MAYS) FROM MISIONES (ARgENTINA)
}

\author{
Pedro Melchiorre $^{1 *} \mathbb{\oplus}$, Norberto Bartoloni² ${ }^{2}$ y Julián A. Cámara Hernández $\dagger^{1}$
}

\begin{abstract}
1. Cátedra de Botánica Sistemática Facultad de Agronomía, Universidad de Buenos Aires. Avda. San Martín 4453, 1417 Buenos Aires, Argentina. 2. Cátedra de Métodos Cuantitativos Aplicados. Facultad de Agronomía, Universidad de Buenos Aires. Avda. San Martín 4453,1417 Buenos Aires, Argentina.
\end{abstract}

*melchior@mail.agro.uba.ar

Citar este artículo

MELCHIORRE, P., N. BARTOLONI \& J. A. CÁMARA HERNÁNDEZ†. 2020. Relaciones fenotipícas y genéticas entre razas tardías de maíz (Zea mays ssp. mays) nativas de la provincia de Misiones (Argentina). Bol. Soc. Argent. Bot. 55: 23-43.

DOI: https://doi. org/10.31055/1851.2372.v55. n1.22126

Recibido: 26 Noviembre 2018 Aceptado: 30 Enero 2020 Publicado: 25 Marzo 2020 Editora: Viviana Solis Neffa (ic

ISSN versión impresa 0373-580X ISSN versión on-line 1851-2372

\section{SUMMARY}

Background and aims: Although the races of maize native to the Northeast of Argentina (Misiones) have been described and a work on phenetic relations has been published, nevertheless little is known about genetic relationships, this being the main objective of this work.

M\&M: A group of 6 races of maize and the " $F_{1}$ " offspring of crosses derived from a diallel scheme have been evaluated on the basis of 21 morphological vegetative, reproductive and phenological quantitative traits using ANOVA and multivariate statistical methods (discriminant canonic analysis and cluster analysis).

Results: The ANOVA showed highly significant differences among parental races and progeny for almost all the variables. The first two canonical variables (CV) explain almost $67 \%$ of overall variation. The most important discriminating characters associated with the first $\mathrm{CV}$ correspond to dimensions of ears and grains, while the traits contributing to the second CV are related mainly to vegetative and reproductive morphology. Racial groups defined by cluster analysis were described.

Conclusions: Cluster analysis allowed distinguishing related racial groups. The genetic relationships observed from diallel crosses are different according to the parameter considered for regrouping. The results obtained are important from the taxonomic and evolutionary point of view and facilitate the choice of material to be used in breeding programs.

\section{KEY WORDS}

Diallel crosses, evolution, germplasm of maize, maize breeding, maize landraces, numerical taxonomy.

\section{REsumen}

Introducción y objetivos: Si bien se han descripto las razas de maíz nativas del Noreste de Argentina (Misiones) y publicado un trabajo sobre las relaciones fenéticas, no obstante poco se conoce sobre las relaciones genéticas, siendo éste el objetivo principal de este trabajo.

M\&M: Un grupo de seis razas de maíz y la descendencia " $F_{1}$ " derivada de un esquema de cruzamientos dialélicos han sido evaluadas sobre la base de 21 caracteres cuantitativos, morfológicos vegetativos, reproductivos y fenológicos mediante ANVA y métodos estadísticos multivariados (análisis discriminante canónico y análisis de agrupamiento).

Resultados: El ANVA mostró diferencias altamente significativas entre las razas parentales y la progenie, para casi todas las variables. Las dos primeras variables canónicas (VC) explican casi $67 \%$ de la variación total. Los caracteres discriminantes más importantes asociados a la primera VC corresponden a las dimensiones de la espiga y de los granos, mientras que los caracteres ligados a la segunda VC son morfológicos vegetativos y reproductivos. Se describieron los grupos raciales definidos por el análisis de agrupamiento.

Conclusiones: El análisis de agrupamiento permitió distinguir grupos raciales afines. Las relaciones genéticas observadas a partir de cruzamientos dialélicos son diferentes según el parámetro que se considere para el reagrupamiento. Los resultados obtenidos son importantes desde el punto de vista taxonómico y evolutivo y facilitan la elección de material a emplear en los programas de mejoramiento.

\section{Palabras clave}

Cruzamientos dialélicos, evolución, germoplasma de maíz, mejoramiento de maíz, razas de maíz, taxonomía numérica. 


\section{INTRODUCCIÓN}

En el Norte de la Argentina se conocen más de 50 razas nativas de maíz, las que fueron descriptas y clasificadas en forma parcial en sucesivos trabajos (Abiusso \& Cámara Hernández, 1974; Cámara Hernández \& Miante Alzogaray, 1979, 1981; Miante Alzogaray et al., 1996) y más recientemente fueron publicadas en forma integral (Cámara Hernández et al., 2012). En el Noreste de la Argentina (NEA), en particular en la provincia de Misiones, existe una gran diversidad de formas de maíz nativas e introducidas (Girola, 1919; Parodi, 1935, 1947, 1966; Brieger et al., 1958; Luna et al., 1964; Torregrosa et al., 1980; Catálogo INTA, 1997). Debido a ello, esta zona es considerada como parte de un segundo centro de variabilidad genética del norte de la Argentina, después de la región andina. El maíz ("avati" o “abati”, en guaraní) fue cultivado por los guaraníes y por sus descendientes, desde muchos siglos antes de la conquista del Río de la Plata (Parodi, 1935) $\mathrm{y}$, aún en el presente, se ubica entre sus principales cultivos. Existen varios trabajos relativamente recientes sobre las razas de maíz autóctonas del Norte de Argentina. Estos trabajos ponen su acento sobre la caracterización genética y la variabilidad citogenética (Poggio et al.,1998; Rosato et al., 1998; Lía, 2004; Bracco, 2008; Bracco et al., 2008, 2012, 2016; Fourastié, 2010, 2015; Fourastié et al., 2017; Realini, 2017; Realini et al., 2016, 2018); sobre la quimiometría (Robutti et al., 2000), la androesterilidad (Frayssinet et al., 2001), el premejoramiento de poblaciones locales de maíz (Hourquescos et al., 2003) y la incorporación de germoplasma indígena de maíz en materiales elite (Eyherabide, 2004). Esta información revela y confirma la amplia variabilidad genética existente en las razas nativas de Argentina y la importancia que tiene la preservación, caracterización, evaluación y utilización de la misma como fuente de germoplasma.

En la provincia de Misiones se delimitaron 14 razas nativas y otras introducidas (Cámara Hernández \& Miante Alzogaray, 2003). Posteriormente, a partir de muestras originales de esas razas, se realizó una evaluación preliminar de las relaciones fenéticas entre las mismas (Melchiorre et al., 2006). La evaluación fenotípica de una colección de germoplasma es indispensable en una primera etapa del conocimiento de la variabilidad presente, pero no es suficiente para conocer la naturaleza de las diferencias genéticas que caracterizan el material en estudio. La información más detallada sobre cuánto de esa variabilidad no es imputable al ambiente requiere una evaluación genética. Sobre la base de la clasificación en razas y de las relaciones fenéticas encontradas, se realizaron cruzamientos según un esquema dialélico completo. La evaluación conjunta de la descendencia " $F_{1}$ " y de las poblaciones parentales permitirá comprender los efectos genéticos involucrados en controlar los caracteres cuantitativos y conocer las posibilidades potenciales que presenta el material para ser utilizado en programas de mejoramiento (Griffing, 1956; Bianchi et al., 1973).

Los estudios previos de los factores genéticos (Horovitz, 1935), revelaron que las formas de maíz cultivadas en la región Guaranítica presentan características propias y definidas que las diferencian de aquellas otras cultivadas en los valles altos andinos del noroeste argentino.

La importancia de conservar las poblaciones locales radica en que las mismas se encuentran bien adaptadas al área geográfica de origen (con clima y suelos definidos) y a las necesidades y costumbres de los agricultores. Además, constituyen una fuente potencial de germoplasma importante para su empleo en el mejoramiento genético, dado que, durante el proceso evolutivo, se retienen genes o combinaciones de genes favorables para el rendimiento y/ o resistencia a la sequía y a la aparición de nuevas razas de agentes patógenos o insectos.

La evaluación conjunta, fenotípica y genética de poblaciones locales, realizada mediante métodos estadísticos multivariados basados en caracteres cuantitativos ligados a la producción de granos, a la forma de la planta y al ciclo vegetativo, permite realizar una descripción sintética de la variabilidad total y definir en qué medida cada carácter contribuye a explicar las diferencias existentes entre poblaciones (Camussi et al., 1983). Por otro lado, los caracteres cuantitativos utilizados para la descripción y clasificación de los grupos (a diferencia de algunos otros caracteres tradicionalmente usados en la clasificación de razas, como la forma de la espiga, el color y la textura de los granos) están más directamente vinculados con la adaptación a las condiciones agroclimáticas y son 


\section{P. Melchiorre et al. - Relaciones fenotípicas y genéticas entre las razas de maíz nativas, Misiones}

más adecuados para determinar el grado de afinidad entre poblaciones raciales. Asimismo, la mayor parte de los cambios involucrados en la microevolución de las poblaciones ocurren en los caracteres de variación continua (Falconer \& Macakay, 1996).

La clasificación de las formas raciales en grupos con características discriminantes comunes, favorece la conservación de la variabilidad genética dispersa en las diferentes muestras y la selección posterior de los materiales más representativos. Además, esta categorización facilita la creación de nuevos y mejores genotipos (Rodríguez et al., 1968). En particular, la evaluación de los parámetros genéticos de las poblaciones raciales es importante en los estudios sobre clasificación, origen y evolución de las razas locales de maíz y permite conocer la potencialidad que presenta el material para su utilización en programas de mejoramiento.

La evaluación del material utilizado se realizó en una localidad de la provincia de Misiones lo más similar posible al hábitat de procedencia de las muestras originales, y simultáneamente en la ciudad de Buenos Aires, para estimar la posible interacción genotipo-ambiente. En particular el estudio de la interacción genotipo-ambiente $(\mathrm{G} \times \mathrm{A})$ es de relevancia en la etapa final del mejoramiento genético de una especie, siendo uno de los factores determinantes en la selección de materiales, debido a que la respuesta puede no ser la misma en distintos ambientes.

Por las razones expuestas, los objetivos de este trabajo son: (a) reagrupar las poblaciones afines sobre la base de múltiples caracteres cuantitativos, (b) determinar en qué medida contribuye cada carácter a explicar las diferencias entre las poblaciones raciales, (c) realizar una descripción sintética de la variabilidad total (d) determinar y comparar las relaciones fenéticas y genéticas, (e) evaluar y comparar los cruzamientos recíprocos con los cruzamientos directos y (f) estimar la interacción genotipo-ambiente.

\section{Materiales y Métodos}

En este trabajo se consideraron 6 poblaciones raciales de maíz, tardías y semi-tardías: Amarillo Ancho, Pipoca Amarillo, Pipoca Colorado, Pororó Chico, Pororó Grande y Tupí Amarillo, originarias de Misiones (Tabla 1). En el ciclo primaveraverano 2005-06 se hicieron siembras escalonadas en Buenos Aires (Jardín Botánico de la Cátedra de Botánica Agrícola de la Facultad de Agronomía de la Universidad de Buenos Aires (FAUBA) para efectuar cruzamientos según un esquema dialélico completo (cruzamientos directos y recíprocos).

A partir de las espigas correspondientes a la progenie de los cruzamientos " $\mathrm{F}_{1}$ " derivados y de las razas parentales, se obtuvieron las muestras de granos para su evaluación. Además, se incluyeron en la evaluación a dos variedades comerciales como testigos. El cultivo experimental se realizó en Jardín Botánico de la Cátedra de Botánica de FAUBA y en Misiones, localidad de Ruiz de Montoya (Depto. Libertador General San Martín). Ruíz de Montoya

Tabla1. Genotipos parentales, número de colección, localidades de procedencia de las muestras y longitud del ciclo vegetativo.

\begin{tabular}{|lcccc|}
\hline \multicolumn{1}{|c}{$\begin{array}{c}\text { Razas parentales (código) } \\
\text { y nombres locales }\end{array}$} & No de colección & Localidad de origen & Depto. & LCV \\
\hline $\begin{array}{l}\text { Amarillo Ancho (A) Avatí Ju } \\
\text { Pipoca Colorado (P11) }\end{array}$ & VAV 6569 & Aldea Pozo Azul & El Dorado & 80 \\
Pipoca Amarillo (P12) & VAV 6568 & Aldea Pozo Azul & El Dorado & 82 \\
Pororó Chico (P13) avatí pororó, maíz 5 meses & VAV 6575 & Aldea MBY'A, Guaraní, & San Pedro & 85 \\
& & Guavyra Pory, Guaraní, & \\
Pororó Grande (P14) avatí pororó & & Pasaje Paraiso & \\
Tupí amarillo (T) avatí Tupí, maíz duro & VAV 6562 & Aldea Chiripá Guaraní & Guaraní & 86 \\
\hline
\end{tabular}

Referencias. LCV: número de días desde la siembra a la antesis de las flores masculinas. 
está ubicada a $26^{\circ} 58^{\prime} 60^{\prime \prime}$ de latitud sur, $55^{\circ} 2^{\prime} 60^{\prime \prime}$ de longitud oeste y con una altitud de $166 \mathrm{msnm}$, clima subtropical, temperatura anual promedio de $21{ }^{\circ} \mathrm{C}$, precipitaciones abundantes y regulares de $1000-1800 \mathrm{~mm}$ y suelos rojizos. En Buenos Aires, el Jardín Botánico está ubicado a $34^{\circ} 35^{\prime}$ de latitud sur, 58 $29^{\circ}$ de longitud oeste, y con una altitud $25 \mathrm{msnm}$. La temperatura media anual de $16,9{ }^{\circ} \mathrm{C}$ y la precipitación media anual de 1027,3 mm. En Misiones, la siembra se realizó el 6 de octubre de 2006 según un diseño experimental en bloques completos aleatorizados con 3 repeticiones (38 parcelas por bloque). Cada parcela, de 12 $\mathrm{m}^{2}$, consistió de 3 surcos de $5 \mathrm{~m}$ de longitud y a una distancia de $75 \mathrm{~cm}$ entre surcos. Con algunas excepciones, se sembraron 36 granos por parcela, con 12 granos por surco separados $33,33 \mathrm{~cm}$ y a una profundidad de $5 \mathrm{~cm}$. La siembra se realizó en forma manual y con el uso de un marcador de profundidad $\mathrm{y}$ de distancia. Los cultivos correspondientes en Buenos Aires se limitaron (por falta de espacio y a veces de granos) a la siembra en surcos con 12-15 granos por cada genotipo. Posteriormente, en el cultivo, se señalaron sucesivamente las hojas expandidas número 3,6 y 12 , sobre 12 plantas competitivas por parcela, para facilitar posteriormente el registro del número de hojas y el relevamiento de los demás caracteres morfológicos vegetativos. Los siguientes caracteres considerados fueron los mismos que se utilizaron en trabajos anteriores (Camussi et al., 1983; Melchiorre, 1992; Melchiorre et al., 2017).

Caracteres morfológicos vegetativos: altura hasta la inserción de la espiga distal (AES), número de hojas a la espiga distal (NHES), altura total de la planta (AT), número total de hojas/planta (HT) y número de macollos (NM).

Caracteres fenológicos: tiempo hasta la floración masculina (FM) y la floración femenina (FF), en días desde la siembra.

Caracteres reproductivos: número de espigas por planta (NE), peso de la espiga distal (PE), producción total de espigas/planta (PET), número de hileras de granos/espiga (NHI), número de cariopses por hilera (CHI), longitud de la espiga (LE), diámetro de la espiga en el ápice (DEA), diámetro de la espiga en la base (DEB), diámetro de la espiga en el punto medio (DEM), peso de 50 cariopses (P50C), longitud de 10 cariopses (LC), ancho de 10 cariopses (AC), espesor de 10 cariopses (EC).
Caracteres derivados: Índices EC/LC y DEM/LE

El relevamiento de cada carácter se realizó sobre cada una de las 12 plantas previamente señaladas con excepción del número de macollos y los datos de floración (tiempo hasta la floración masculina y femenina) que se obtuvieron sobre el total de plantas de cada parcela. Para el análisis posterior de los datos se tuvieron en cuenta solo aquellas plantas de las que se disponían de los datos completos (de campo y de laboratorio).

\section{Métodos estadísticos}

A partir del conjunto de datos obtenidos sobre plantas individuales, se confeccionó la matriz básica de datos que incluía los datos de los genotipos parentales, de la progenie de los cruzamientos " $F_{1}$ " (directos y recíprocos por separado) y de los dos testigos. Esta matriz fue procesada mediante ANVA y técnicas estadísticas multivariadas: análisis discriminante canónico (ADC) y análisis de agrupamiento (AA).

Además del ANVA, para cada carácter se calculó el coeficiente de variación (CV), expresado como porcentaje de los desvíos estándar, respecto a la media aritmética. Ello permite hacer comparaciones de los caracteres (aunque tengan diferentes unidades de medida) y da una idea del grado de representatividad de las medias aritméticas.

\section{Análisis discriminante canónico}

Una de las ventajas del empleo del análisis discriminante canónico para el estudio de las diferencias entre las poblaciones raciales es que permite resumir la variabilidad total en pocas variables sintéticas (variables canónicas, VC). Éstas además, permiten maximizar las diferencias entre poblaciones en relación con las diferencias dentro de las mismas, al considerar a cada individuo como la unidad experimental. Asimismo, las VC son utilizadas para calcular las distancias fenotípicas, las diferentes clases de efectos genéticos y así las distancias genéticas, para la clasificación fenotípica y/o genética del grupo (Camussi \& Ottaviano, 1979; Ottaviano \& Camussi, 1981; Camussi et al. 1983, 1985).

\section{Análisis de agrupamiento}

A partir de las variables canónicas se obtuvieron las matrices de distancias fenotípicas y genéticas, previa obtención de los parámetros genéticos. Para 


\section{P. Melchiorre et al. - Relaciones fenotípicas y genéticas entre las razas de maíz nativas, Misiones}

el cálculo se empleó el coeficiente de distancia euclidiana. El agrupamiento de las poblaciones parentales y cruzamientos se realizó (en ambos casos) por medio del método UPGMA (Unweighted Pair-Group Method using Arithmetic average) (Sneath \& Sokal, 1973).

\section{Análisis genético}

La estimación de los parámetros genéticos (para las 5 primeras variables canónicas) se basó en el modelo genético lineal de Gardner \& Eberhardt (1966):

$$
\begin{aligned}
& \xi_{j j^{\prime} i}=\mu_{i}+\frac{1}{2}\left(v_{j i}+v_{j^{\prime} i}\right)+\gamma\left(\bar{h}_{i}+h_{j i}+h_{j^{\prime} i}+s_{j j^{\prime} i}\right) \\
& \text { con } \\
& \gamma=\left\{\begin{array}{ll}
0 & \text { para } j=j^{\prime} ; j, j \\
1 & \text { para } j \neq j^{\prime}
\end{array} ;, j^{\prime}=1,2, \ldots, m>3 .\right.
\end{aligned}
$$

donde $\boldsymbol{x}_{i j i}$ es un parámetro que representa el efecto o esperanza de un cruzamiento entre las poblaciones $j$-ésima y $j$ '-ésima, $m_{i}$ es la esperanza promedio para las poblaciones parentales, $v_{j i}$ es el efecto poblacional de la $j$-ésima población como uno de los padres, $\bar{h}_{i}$ es la heterosis promedio de todos los cruzamientos, $h_{j i}$ es el efecto de heterosis debido a la $j$-ésima población (una contribución constante de la $j$-ésima población a la heterosis de todos los cruzamientos en los cuales esa población entra como uno de los padres) y $s_{i j}$, $i$ es la heterosis específica para el cruzamiento entre las poblaciones $j$-ésima y $j$ '-ésima.

En el análisis genético, los cruzamientos recíprocos por lo general no son considerados, porque dan descendencias iguales o equivalentes a los cruzamientos directos. Sin embargo, algunas veces se observan diferencias significativas en caracteres como, por ejemplo, los días hasta la floración masculina $y / o$ femenina o en otros caracteres componentes del rendimiento (Hiorth, 1985), razón por la cual en este trabajo también se analizaron por separado los efectos recíprocos y se compararon con los resultados de los cruzamientos directos.

La descripción de los grupos resultantes del análisis fenotípico y genético se realizó sobre la base de categorías establecidas a partir de los valores promedios de las variables originales (Tabla 2). Las categorías fueron obtenidas restando del valor medio mayor, el valor medio menor correspondiente y dividido por cuatro (número de categorías). Finalmente, a fin de evaluar la interacción genotipo $\times$ ambiente se compararon los promedios de las variables analizadas en las plantas cultivadas en FAUBA y en las cultivadas en Misiones.

Las espigas más representativas y las muestras de granos utilizadas para las mediciones son conservadas en el Laboratorio de Recursos Genéticos N.I. Vavilov de la Facultad de Agronomía de la Universidad de Buenos Aires. Los agrupamientos fueron obtenidos con el programa NTSYS (Rohlf, 1993).

\section{Resultados}

El ANVA mostró diferencias altamente significativas entre las razas parentales, la progenie y las dos variedades comerciales utilizadas como testigo, para todas las variables consideradas. Los CV mostraron los valores más bajos (7-19\%), en los caracteres de la espiga (longitud de la espiga, diámetro de la espiga en el ápice, diámetro de la espiga en la base y diámetro de la espiga en el punto medio), de los granos (longitud de 10 cariopses, ancho de 10 cariopses y espesor de 10 cariopses), de la planta (altura total de la planta, número total de hojas/planta, número de hojas a la espiga distal) y al índice DEM/LE. Los valores de CV más altos, superiores al $40 \%$, se registraron en los caracteres peso de la espiga distal, producción total de espigas/planta y número de espigas por planta. Valores medios bajos $(\mathrm{CV}=20-31 \%)$ se observaron en altura hasta la inserción de la espiga distal, número de cariopses por hilera y el índice EC/ LC. Mientras que valores medios altos $(\mathrm{CV}=31$ $40 \%$ ) corresponden al peso de los cariopses. Los resultados del ANVA sobre la comparación de las medias correspondientes a los datos obtenidos en el Jardín Botánico (Buenos Aires) y la localidad Ruíz de Montoya (Misiones) mostraron, en general, diferencias altamente significativas o significativas entre sitios de cultivos y entre genotipos, así como la existencia de interacción genotipo $x$ ambiente (Tabla 3). Asimismo, de la comparación de los promedios originales de cada variable entre sitios de cultivo, surge que los promedios de los caracteres morfológicos vegetativos (altura total de la planta, altura hasta la inserción de la espiga distal, número de hojas a la espiga distal y número total de hojas/planta), de los caracteres fenológicos (tiempo hasta la floración masculina y tiempo hasta 


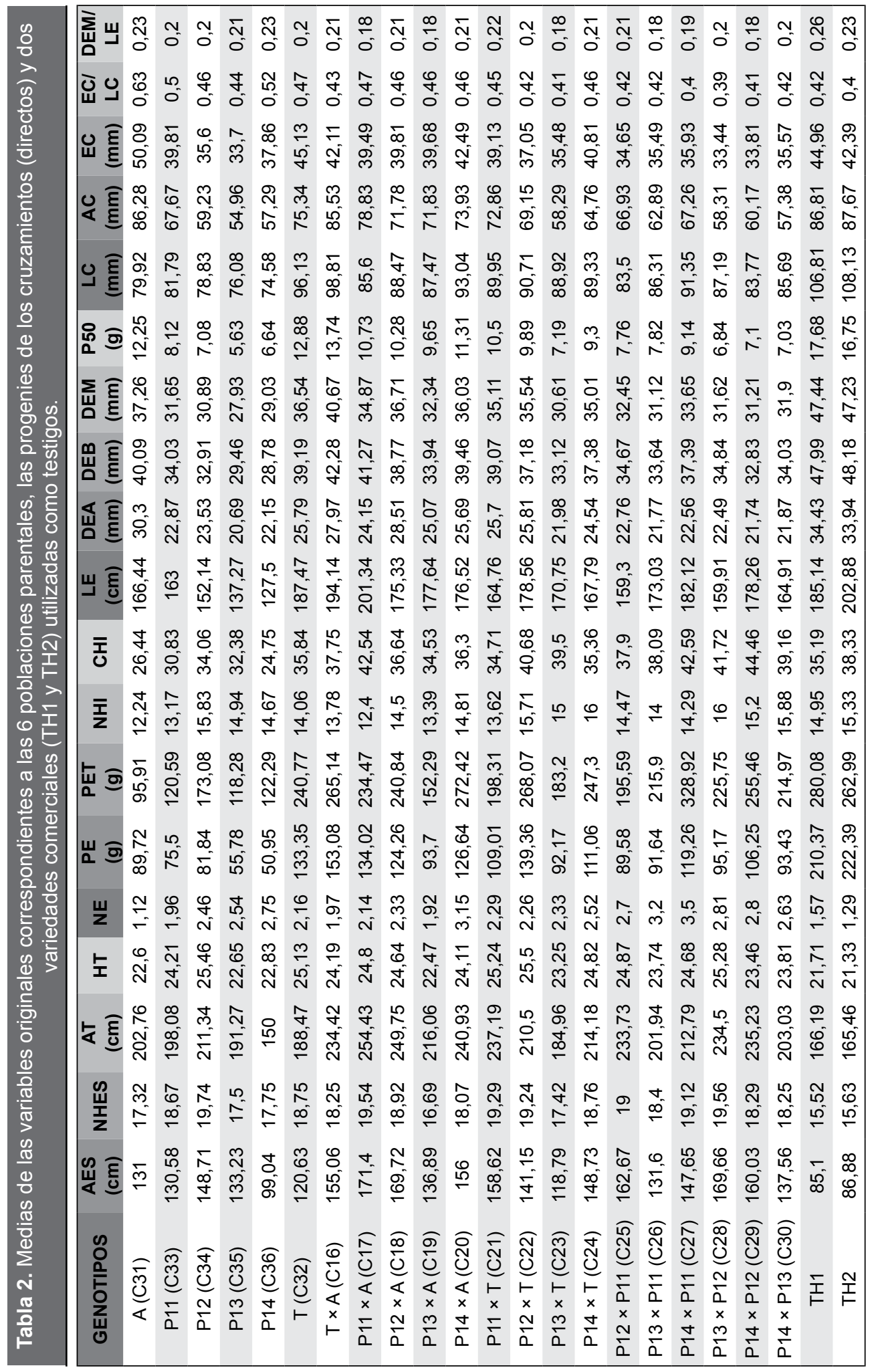

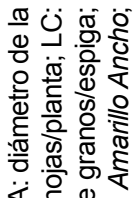

岀守要

무웡

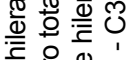

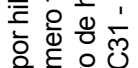

के 월 的

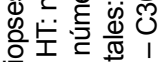

कृ

O)

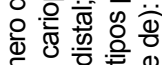

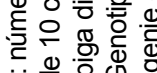

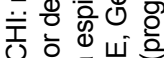

is

ه क

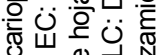

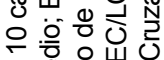

8 \&

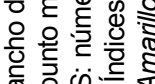

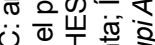

نิ

要

증 흥 曹.

त $\frac{1}{4}$ 은

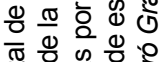

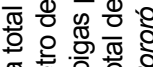

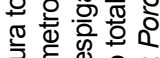

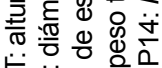

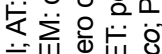

需㟔

응

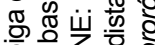

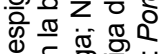

ब

कृ. 융 क्ष

:응 $\frac{0}{0} \frac{\pi}{0} \frac{\pi}{0}$

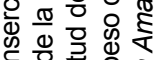

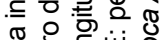

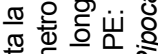

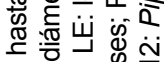

을

폳

峲

$\varangle$

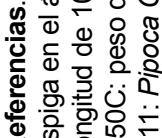


Tabla 3. Comparación de los valores promedio de las variables analizadas entre sitios de cultivo (S) (Misiones y Buenos Aires), entre genotipos $(G)$ y la interacción genotipo $\times$ ambiente $(G \times S)$ : resultados del ANVA y niveles de significancia.

\begin{tabular}{|cccc|}
\hline Caracteres & SITIO (S) & GENOTIPO (G) & $($ G $\times$ S) \\
AES & $n s$ & $* *$ & $* *$ \\
NHES & $* *$ & $* *$ & $* *$ \\
AT & $* *$ & $* *$ & $* *$ \\
HT & $* *$ & $* *$ & $* *$ \\
FM & $* *$ & $* *$ & $* *$ \\
FF & $* *$ & $* *$ & $* *$ \\
PE & $* *$ & $* *$ & $* *$ \\
PET & $* *$ & $* *$ & $* *$ \\
NHI & $* *$ & $* *$ & $* *$ \\
CHI & $* *$ & $* *$ & $* *$ \\
LE & $* *$ & $* *$ & $* *$ \\
DEA & $n s$ & $* *$ & $* *$ \\
DEB & $* *$ & $* *$ & $* *$ \\
DME & $* *$ & $* *$ & $* *$ \\
P50C & $* *$ & $* *$ & $n s$ \\
LC & $* *$ & $* *$ & $*$ \\
AC & $n s$ & $* *$ & $*$ \\
EC & $* *$ & $* *$ & $* *$ \\
EC/LC & $* *$ & $* *$ & $* *$ \\
DEM/LE & $* *$ & $* *$ & $* *$ \\
\hline
\end{tabular}

Referencias. AC: ancho de 10 cariopses; AES altura hasta la inserción de la espiga distal; NHES: número de hojas a la espiga distal; AT: altura total de la planta; $\mathrm{CHI}$ : número de cariopses por hilera; DEA: diámetro de la espiga en el ápice; DEB: diámetro de la espiga en la base; DEM: diámetro de la espiga en el punto medio; P50C: peso de 50 cariopses; EC: espesor de 10 cariopses; FF: floración femenina; FM: floración masculina; HT: número total de hojas/planta; LC: longitud de 10 cariopses; LE: longitud de la espiga; NE: número de espigas por planta; NHI: número de hileras de granos/ espiga; PE: peso de la espiga distal; PET: peso total de espigas/planta; Indices EC/LC y DEM/LE. * $p \leq 0,05 ;{ }^{* *} p$ $\leq 0,01 ; n s=$ no significativo $(p>0,05)$.

la floración femenina), del cariopse (ancho y espesor de 10 cariopses) y de los índices EC/LC y DEM/LE son, en general, mayores en las plantas del cultivo realizado en Buenos Aires que los promedios obtenidos en las del cultivo de Ruiz de Montoya
(Misiones). A la inversa, los valores promedios de los caracteres de las espigas (número de espigas por planta, peso de la espiga distal, producción total de espigas/planta, longitud de la espiga, número de hileras de granos/espiga y diámetro de la espiga en el punto medio) y de los cariopses (número de cariopses por hilera y longitud de 10 cariopses), son relativamente mayores en las plantas cultivadas Misiones que los promedios obtenidos en las cultivadas en Buenos Aires.

El relevamiento del número de macollos/planta, se realizó a nivel de parcela, registrándose la ausencia de macollos o la presencia de 1, 2, 3 ó 4 macollos/planta. En algunas parcelas el número de macollos fue prácticamente nulo (por ejemplo, entre otras, la raza Amarillo Ancho y la progenie del cruzamiento Pipoca amarillo $\times$ Pororó grande) . En el $70 \%$ de las plantas se registró un macollo por planta; en el $24 \%$ dos macollos por planta y en el 5\% tres macollos por planta. En las razas parentales, a excepción de la raza Amarillo Ancho, el $51 \%$ de las plantas presentó un macollo, el 35,5\% dos macollos y el $13 \%$ tres macollos por planta.

Los resultados del análisis discriminante canónico indican que las cinco primeras variables canónicas (VC) resumen el $87 \%$ de la variación total, mientras que las dos primeras VC explican casi el $67 \%$ de las diferencias (Tabla 4). Esto indica que las dos primeras VC son suficientes para una buena representación gráfica y una descripción sintética de la variabilidad total. Los coeficientes de correlación entre las variables originales y las variables canónicas permiten (por su magnitud y signo), la interpretación biológica de las VC. En la Tabla 4, se observa que la primera VC discrimina a las poblaciones principalmente por la anchura y el peso del cariopse. Valores menores de correlación se observan para las dimensiones de las espigas (diámetro de la espiga en el ápice, diámetro de la espiga en la base, diámetro de la espiga en el punto medio, longitud de la espiga y número de hileras de granos/espiga) y el peso de la espiga distal por planta. Los caracteres discriminantes más importantes ligados a la segunda $\mathrm{VC}$ son la altura hasta la inserción de la espiga distal, la altura total de la planta, la longitud de la espiga y el número de granos por hilera. Los caracteres discriminantes más importantes ligados a la tercera VC son el número de hojas hasta la espiga distal, número total de hojas, el peso de la espiga distal 


\section{Tabla 4. Coeficientes de correlación entre las} variables originales y las 5 primeras variables canónicas (VC) resultantes del análisis

discriminante canónico. Se destacan los valores más significativos y se multiplican por 100: la magnitud de los coeficientes sugieren qué caracteres son los más importantes. En la parte inferior se muestran los autovalores y los porcentajes acumulados.

\begin{tabular}{|c|c|c|c|c|c|}
\hline \multirow{2}{*}{ Caracteres } & \multicolumn{5}{|c|}{ Variables canónicas } \\
\hline & 1 & 2 & 3 & 4 & 5 \\
\hline AES & 9 & 52 & 3 & -52 & 13 \\
\hline NHES & 0 & 24 & 52 & -39 & -44 \\
\hline AT & 17 & 61 & 3 & -44 & 23 \\
\hline HT & 3 & 21 & 69 & -32 & -19 \\
\hline NE & -14 & 14 & 10 & 1 & 9 \\
\hline PE & 21 & 30 & 44 & 6 & 26 \\
\hline PET & 2 & 29 & 37 & 2 & 13 \\
\hline NHI & -20 & -31 & 31 & -29 & 34 \\
\hline $\mathrm{CHI}$ & 6 & 58 & 23 & 4 & 14 \\
\hline LE & 23 & 45 & 22 & 36 & 14 \\
\hline DEA & 36 & -16 & 11 & -19 & 41 \\
\hline DEB & 37 & 24 & 36 & 4 & 6 \\
\hline DEM & 37 & 7 & 38 & 0 & 37 \\
\hline P50C & 43 & 0 & 32 & 25 & 24 \\
\hline LC & 11 & 18 & 37 & 26 & 39 \\
\hline$A C$ & 66 & 8 & 5 & 23 & 10 \\
\hline EC & 37 & -33 & 6 & 24 & 4 \\
\hline EC/LC & 16 & -35 & -22 & 5 & -26 \\
\hline DME/LE & 7 & -35 & 6 & -31 & 7 \\
\hline Eigenvalor & 4.61 & 1.29 & 0.75 & 0.66 & 0.4 \\
\hline $\begin{array}{c}\text { Porcentaje } \\
\text { acumulado (\%) }\end{array}$ & 52.1 & 66.69 & 75.22 & 82.68 & 87.2 \\
\hline
\end{tabular}

Referencias. AES: altura hasta la inserción de la espiga distal; AC: ancho de 10 cariopses; AT: altura total de la planta; $\mathrm{CHI}$ : número de cariopses por hilera; DEA: diámetro de la espiga en el ápice; DEB: diámetro de la espiga en la base; DEM: diámetro de la espiga en el punto medio; EC: espesor de 10 cariopses; HT: número total de hojas/planta; LC: longitud de 10 cariopses; LE: longitud de la espiga; NE: número de espigas por planta; NHES: número de hojas a la espiga distal; NHI: número de hileras de granos/espiga; P50C: peso de 50 cariopses; PE: peso de la espiga distal; PET: peso total de espigas/planta; Índices: EC/LC; DEM/LE. y la producción total de espigas por planta. Para la cuarta $\mathrm{VC}$, el carácter de mayor peso relativo es la altura de inserción de la espiga distal. La quinta VC se encuentra correlacionada, al igual que la tercera $\mathrm{VC}$, con el número de hojas hasta la inserción de la espiga distal pero con signo negativo.

En el diagrama de dispersión (Fig. 1), los puntos (valores medios de la primera y segunda VC) C16-C30 representan a las progenies y C31-C36 a las poblaciones parentales. Las relaciones entre los genotipos están dadas por la posición que éstos ocupan en el espacio delimitado por los ejes canónicos, es decir, cuanto más cercanos se encuentren entre sí, tendrán un mayor grado de afinidad.

La primera VC discrimina a los genotipos por las diferencias entre los caracteres referidos a las dimensiones y peso de los granos y de las espigas asociados a la misma y, en particular, la anchura del cariopse, por ejemplo, la raza Amarillo Ancho se ubica en el extremo positivo del primer eje canónico dado que, posee los granos relativamente más anchos que el resto de los genotipos. Asimismo, Pororó Chico se ubica en el extremo opuesto del mismo eje por poseer espigas y granos relativamente más pequeños. Entre ambos extremos se ubica el resto de las poblaciones parentales y las progenies de los cruzamientos.

La segunda VC separa a los genotipos, principalmente, por los caracteres morfológicos vegetativos (altura total de la planta y altura hasta la inserción de la espiga distal) y otros reproductivos como la longitud de las espigas y el número de granos por hilera, entre otros, asociados a la misma. Por ejemplo, si se consideran las relaciones entre las razas parentales y las progenies, se observa que casi todas las progenies o cruzamientos " $F_{1}$ " (C16-C30) se encuentran ubicadas hacia el extremo (+) del eje canónico 2, lo que indicaría que las mismas tienen plantas de mayor altura, un número mayor de espigas por planta y espigas más pesadas, de mayor longitud y con mayor número de granos por hilera, en comparación con sus progenitores (C31-C36).

\section{Análisis de Agrupamiento}

Los resultados obtenidos utilizando el coeficiente de similitud (distancia euclidiana) para cada par de OTUs, son expresados en una matriz de similitud, a partir de la cual, mediante una técnica adecuada 


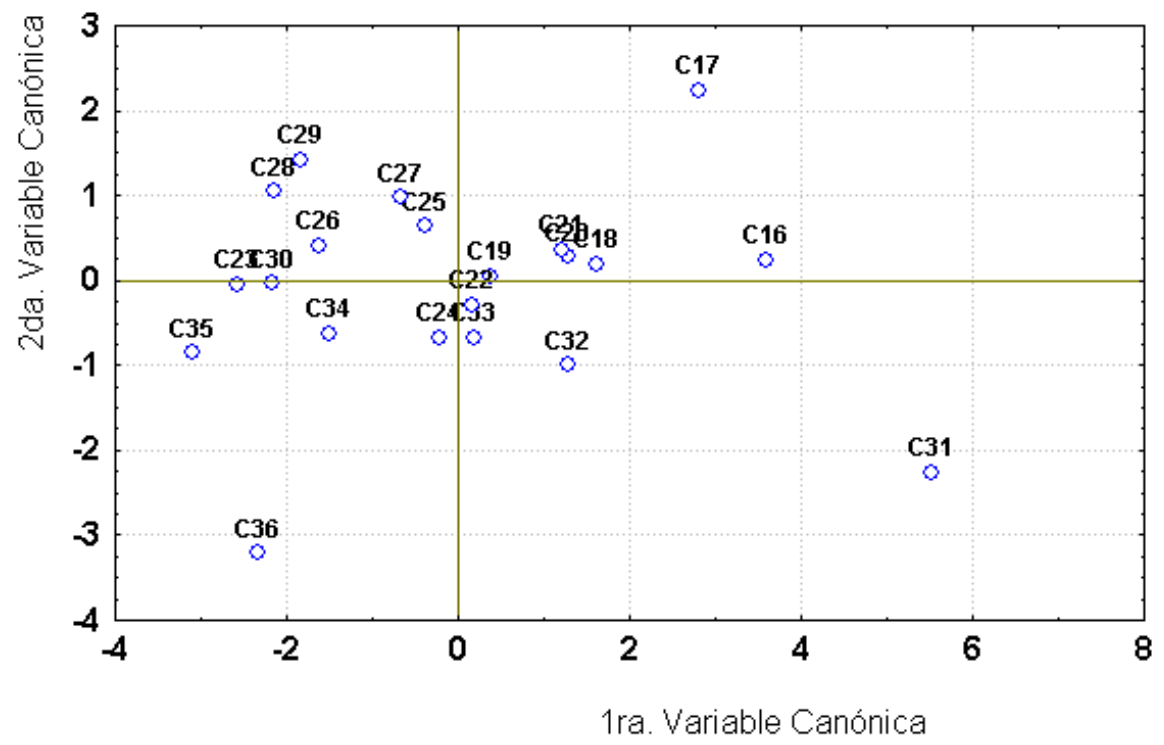

Fig. 1. Diagrama de dispersión de las razas parentales y de la progenie derivadas de sus cruzamientos, según valores medios de las dos primeras variables canónicas resultantes del análisis discriminante canónico. Los puntos o valores medios C16-C30 representan a la progenie y los puntos C31-C36 a las razas parentales.

de agrupamiento como la técnica del ligamiento promedio (que origina una menor distorsión), permitió obtener el fenograma de distancia (Fig. 2). Las relaciones resultantes entre las OTUs se describen a continuación: a un bajo nivel de similitud, se pueden distinguir dos grupos:

Grupo $1\left(\mathrm{G}_{1}\right)$ : está compuesto por las variedades comerciales (TH1 y TH2). Las plantas son relativamente bajas, con 21 o 22 hojas. La espiga distal se inserta ligeramente por encima de la mitad de la altura total, en la hoja 15 o 16. Las espigas (1-2 espigas/planta) son de gran tamaño y muy pesadas, con 15-16 hileras y con un número medianamente alto de granos por hilera. Los granos son pesados, largos, anchos y de un espesor medio-alto. El valor del índice EC/LC es bajo, mientras que el índice $\mathrm{DEM} / \mathrm{LE}$ es alto o medio-alto. Además, presentan los valores promedios más altos, en cuanto a los caracteres: peso, longitud, espesor, anchura de los granos y de las espigas.

Grupo $2\left(\mathrm{G}_{2}\right)$ : es más amplio y heterogéneo y comprende a las seis poblaciones parentales y a la progenie de los 15 cruzamientos. Se diferencia en dos subgrupos:

Subgrupo A (SA): está integrado por la raza Amarillo Ancho y por la progenie de los cruzamientos Tupí Amarillo $\times$ Amarillo Ancho $(\mathrm{T} \times \mathrm{A})$ y Pipoca Colorado $\times$ Amarillo Ancho $(\mathrm{P} 11 \times \mathrm{A})$. Las plantas de la progenie son de mayor altura, con un mayor número de hojas que las de Amarillo Ancho. El número de espigas por planta y el peso de la espiga distal son bajos en Amarillo Ancho y medio-altos o medio- bajos en la progenie de $(\mathrm{T} \times \mathrm{A})$ y de $(\mathrm{P} 11 \times \mathrm{A})$. El peso de los granos es medio-alto en Amarillo Ancho y ( $\mathrm{T}$ $\times$ A) y medio-bajo en $(\mathrm{P} 11 \times \mathrm{A})$. El peso total de espigas por planta es más alto en la progenie de los cruzamientos que en Amarillo Ancho. La anchura es medio-baja en Amarillo Ancho y en $(\mathrm{P} 11 \times \mathrm{A})$, medio-alta en $(\mathrm{T} \times \mathrm{A})$. La espiga distal se inserta por encima de la mitad de la altura total. El número de granos por hilera es mayor en la progenie que en Amarillo Ancho. Los granos son de longitud variable baja longitud en Amarillo Ancho, medio-alta en $(\mathrm{T} \times \mathrm{A})$ y medio-baja en $(\mathrm{P} 11 \times \mathrm{A})$. La anchura es alta en Amarillo Ancho y 


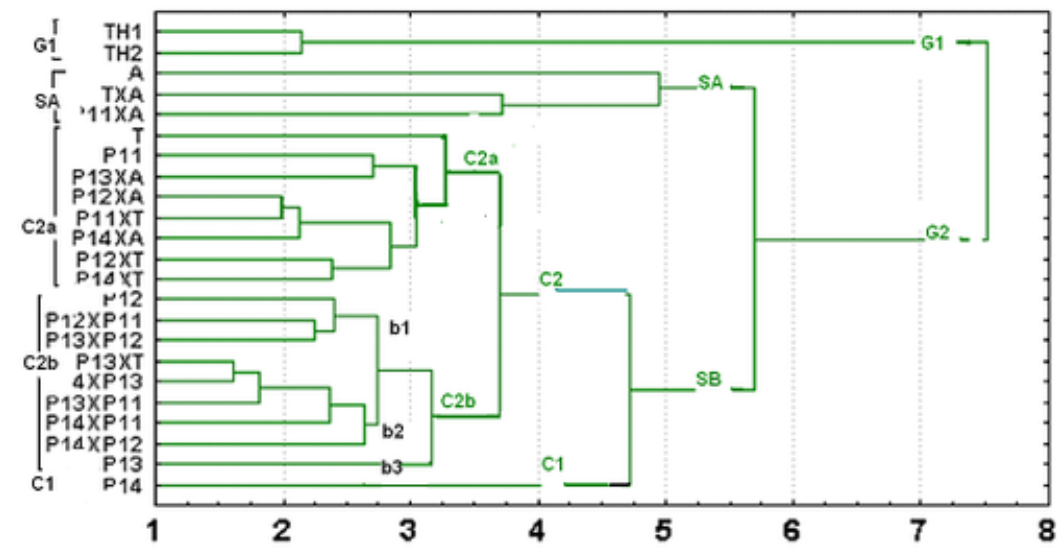

Fig. 2. Fenograma (UPGMA) obtenido a partir de las distancias euclidianas entre las formas raciales parentales y la progenie y dos variedades comerciales ( $\mathrm{TH} 1$ y $\mathrm{TH} 2$ ) empleadas como testigos. Abreviaturas: A: Amarillo Ancho; P11: Pipoca Colorado; P12: Pipoca Amarillo; P13: Pororó Chico; P14: Pororó Grande; T: Tupí Amarillo.

$(\mathrm{T} \times \mathrm{A})$ y medio-alta en $(\mathrm{P} 11 \times \mathrm{A})$. El espesor es alto en Amarillo Ancho, medio-alto en $(\mathrm{T} \times \mathrm{A})$ y medio-bajo en $(\mathrm{P} 11 \times \mathrm{A})$. Los índices $\mathrm{EC} / \mathrm{LC}$ y DEM/LE más elevados corresponden a la raza Amarillo Ancho.

Subgrupo B (SB). Se divide en dos conjuntos: C1 y $\mathrm{C} 2$

C1: está representado por Pororó Grande. Las plantas son bajas con 23 hojas por planta. El número de espigas por planta es medio-alto. La espiga distal tiene 14 hileras con 25 granos por hilera y se inserta por encima de la mitad de la altura total. En cuanto al peso de la espiga distal y al peso total de espigas por planta, la anchura y la longitud de las espigas y el peso de 50 granos y sus dimensiones (longitud, anchura y espesor) son bajos o medio-bajos. Los índices EC/LC y DEM/LE son medio-altos.

$\mathrm{C} 2$ : se diferencia a su vez en dos sub-conjuntos: $\mathrm{C} 2 \mathrm{a}$ y $\mathrm{C} 2 \mathrm{~b}$

Sub-conjunto 1 (C2a): constituido por Tupi Amarillo, relativamente aislado de los demás OTUs y los núcleos: [Pipoca Colorado - Pororó Chico $\times$ Amarillo Ancho $(\mathrm{P} 13 \times \mathrm{A})]$, $[$ Pipoca Amarillo $\times$ Amarillo Ancho $(\mathrm{P} 12 \times \mathrm{A})-$ Pipoca Colorado $\times$ Tupí Amarillo $(\mathrm{P} 11 \times \mathrm{T})]$, Pororó Grande $\times$ Amarillo Ancho $(\mathrm{P} 14 \times \mathrm{A}),[$ Pipoca Amarillo $\times$ Tupí Amarillo $(\mathrm{P} 12 \times \mathrm{T})-$ Pororó Grande $\times$ Tupí Amarillo $(\mathrm{P} 14 \times \mathrm{T})]$. Las plantas de Tupí Amarillo y Pipoca Colorado son de altura medio-baja, mientras que son medio-altas en algunos cruzamientos $(\mathrm{P} 13 \times \mathrm{A}),(\mathrm{P} 12 \times \mathrm{T})$ y $(\mathrm{P} 14 \times \mathrm{T})$, o altas en otros cruzamientos $(\mathrm{P} 11$ $\times \mathrm{T}),(\mathrm{P} 14 \times \mathrm{A})$, con 22-26 hojas. Presentan 2 o 3 espigas por planta y éstas se insertan en el tercio medio ó superior de la altura total. Las espigas son livianas en Pipoca Colorado y (P13 $\times \mathrm{A}),(\mathrm{P} 14 \times \mathrm{T}),(\mathrm{P} 11 \times \mathrm{T})$ y $(\mathrm{P} 14 \times \mathrm{A})$ o mediopesadas en $(\mathrm{P} 12 \times \mathrm{T})$. Tienen 14-16 hileras de granos, poca longitud en Pipoca Colorado o mediana longitud en las restantes OTUs. Tienen una alta cantidad de granos por hilera en (P12 $\times \mathrm{T})$ o medio-alta en las OTUs restantes. El diámetro en el punto medio es bajo en Pipoca Colorado o medio-bajo en las restantes OTUs. El peso total de espigas por planta es bajo en Pipoca Colorado y alto en Tupí Amarillo y en la progenie de los cruzamientos. Los granos son de espesor variable, pudiendo ser cortos y livianos en Pipoca Colorado, medio-largos y pesados Tupí Amarillo y medio-livianos en la progenie de los cruzamientos $(\mathrm{P} 13 \times \mathrm{A}),(\mathrm{P} 12 \times$ $\mathrm{A}),(\mathrm{P} 11 \times \mathrm{T}),(\mathrm{P} 14 \times \mathrm{A}),(\mathrm{P} 12 \times \mathrm{T})$ y $(\mathrm{P} 14 \times \mathrm{T})$, medio-angostos en Pipoca Colorado, $(\mathrm{P} 12 \times \mathrm{T})$ y $(\mathrm{P} 14 \times \mathrm{T})$ o medio-anchos en Tupí Amarillo y la progenie de los cruzamientos $(\mathrm{P} 13 \times \mathrm{A}),(\mathrm{P} 12$ $\times \mathrm{A}),(\mathrm{P} 11 \times \mathrm{T})$ y $(\mathrm{P} 14 \times \mathrm{A})$. Los índices DEM/ LE y EC/LC son bajos o medio-bajos.

Sub-conjunto2 (C2b): se divide a su vez en otros tres sub-conjuntos: b1, b2 y b3 


\section{P. Melchiorre et al. - Relaciones fenotípicas y genéticas entre las razas de maíz nativas, Misiones}

b1: formado por Pipoca Amarillo y la progenie de los cruzamientos Pipoca Amarillo $\times$ Pipoca Colorado $(\mathrm{P} 12 \times \mathrm{P} 11)$, Pororó chico $\times$ Pipoca Amarillo $(\mathrm{P} 13 \times \mathrm{P} 12)$. Las plantas de la progenie son altas y medio-altas en Pipoca Amarillo, con 25-26 hojas, presentando 2-3 espigas, ubicándose la espiga distal, en el tercio superior de la AT, en las hojas 19 ó 20. Las espigas son angostas, medio-livianas en el cruzamiento $(\mathrm{P} 13 \times \mathrm{P} 12)$ o livianas en Pipoca Amarillo, tienen 14-16 hileras de granos, son de poca o mediana longitud y con una cantidad alta o mediana de granos por hilera. El peso total de espigas por planta es intermedioalto en la progenie de los cruzamientos (P12 $\times$ P11) y (P13 × P12) y bajo en Pipoca Amarillo. Los granos son livianos, cortos o medio-cortos Pipoca Amarillo, angostos o medio-angostos $(\mathrm{P} 12 \times \mathrm{P} 11)$ y de poco espesor. El índice DEM/LE es medio-bajo, mientras la relación EC/LC es baja o medio-baja en Pipoca Amarillo.

b2: está formado por la progenie de los cruzamientos Pororó chico $\times$ Tupi $(\mathrm{P} 13 \times \mathrm{T})$, Pororó Grande $\times$ Pororó Chico $(\mathrm{P} 14 \times \mathrm{P} 13)$, Pororó Chico $\times$ Pipoca Colorado $(\mathrm{P} 13 \times \mathrm{P} 11)$, Pororó Grande $\times$ Pipoca Colorado $(\mathrm{P} 14 \times \mathrm{P} 11)$, y Pororó Grande $\times$ Pipoca Amarillo $(\mathrm{P} 14 \times \mathrm{P} 12)$. Las plantas son altas o medio-bajas, con 23-25 hojas, presentando 1-4 espigas por planta, ubicándose la espiga distal en el tercio medio ó en el tercio superior de la AT, en las hojas 17 ó 20. Las espigas, de longitud variable, son livianas en la progenie de los cruzamientos $(\mathrm{P} 13 \times \mathrm{T}),(\mathrm{P} 14 \times \mathrm{P} 13)$ y $(\mathrm{P} 13$ $\times$ P11), o medio-livianas en $(\mathrm{P} 14 \times \mathrm{P} 11),(\mathrm{P} 14$ $\times$ P12); tienen un número alto a medio-alto de hileras de granos (14-16) y una baja cantidad de granos por hilera. El diámetro medio es bajo ó medio-bajo en $(\mathrm{P} 14 \times \mathrm{P} 11)$. El peso total de espigas por planta es variable, registrándose el valor más alto en la progenie del cruzamiento $(\mathrm{P} 14 \times \mathrm{P} 11)$ en relación a todas las demás OTUs. Los granos son pequeños, livianos, angostos o medio-livianos en $(\mathrm{P} 14 \times \mathrm{P} 11)$, medio-cortos y de poco espesor en la progenie de los demás cruzamientos: $(\mathrm{P} 13 \times \mathrm{T}),(\mathrm{P} 14 \times \mathrm{P} 13),(\mathrm{P} 13 \times$ P11), $(\mathrm{P} 14 \times \mathrm{P} 12)$. Los índices EC/LC, DEM/LE son bajos.

b3: está representado por Pororó Chico. Las plantas son medio-altas, con casi 23 hojas de promedio, presentando 1-4 espigas por planta $(2,54 \mathrm{de}$ promedio), ubicándose la espiga distal en el tercio superior de la AT, en las hojas 17 ó 20. Las espigas son cortas y livianas; tienen un número medio-alto de hileras de granos y una cantidad media-baja de granos por hilera. Los diámetros (diámetro de la espiga en el ápice, diámetro de la espiga en la base y diámetro de la espiga en el punto medio) y el peso de las espigas (peso de la espiga distal y producción total de espigas/ planta) son bajos. Los granos son pequeños, livianos, angostos y cortos y de poco espesor. El índice EC/LC es bajo y el DEM/LE es mediobajo.

\section{Análisis Genético}

Cruzamientos directos: En la Tabla 5, se muestra la significancia de los componentes genéticos, correspondiente a cada una de las variables. La heterosis promedio resultó no significativa para el número de hojas hasta la espiga superior, número de hileras de granos, peso de cincuenta cariopses y la anchura de los cariopses, significativa para el número total de hojas por planta y altamente significativa para el resto de los caracteres y los índices EC/LC y DEM/LE. Los efectos de la variedad y de la heterosis varietal fueron todos altamente significativos. Los efectos de la heterosis específica fueron altamente significativos, excepto para las variables número de hileras de granos/ espiga, espesor de 10 cariopses y el índice EC/LC. En la Tabla 6, se muestran las distancias genéticas entre las seis poblaciones raciales obtenidas a partir de los efectos genéticos $\left(v_{i}\right)$. Los valores de distancias entre poblaciones para los efectos $v_{i}$ hallados son todos altamente significativos. El valor más alto de distancia $(221,84)$ se registró entre Amarillo Ancho y Pororó Chico, mientras el valor más pequeño $(75,20)$ correspondió al par Pipoca amarillo Pororó Chico. En la Tabla 7, se muestran las distancias genéticas obtenidas a partir de los efectos de heterosis $\left(h_{i}\right)$. Los valores de distancias entre poblaciones para los efectos $h_{i}$ varían entre 28,80 y 59,65. El valor más alto $(59,65)$ correspondió al par Tupi Amarillo - Pororó Grande y el valor menor $(28,80)$, que resultó no significativo, al par Tupi Amarillo - Pipoca Amarillo. Los valores restantes fueron altamente significativos o significativos: entre Pipoca Colorado - Pipoca Amarillo y Pororó Chico - Pororó Grande.

En los diagramas de dispersión (Figs. 3 y 4) se representan las poblaciones parentales, según las 
Tabla 5. Cruzamientos directos. Niveles de

significancia de las componentes genéticas:

efectos de la variedad (vi) y de la heterosis (hi).

\begin{tabular}{|ccccc|}
\hline Caracteres & $\begin{array}{c}\text { Efectos de } \\
\text { la variedad } \\
\text { (vij) }\end{array}$ & $\begin{array}{c}\text { Efectos de la Heterosis } \\
\text { (h) }\end{array}$ & $\begin{array}{c}\text { Varietal } \\
\text { (hij) }\end{array}$ & $\begin{array}{c}\text { Específica } \\
\text { (sij) }\end{array}$ \\
AES & $* *$ & $* *$ & $* *$ & $* *$ \\
NHES & $* *$ & ns & $* *$ & $* *$ \\
AT & $* *$ & $* *$ & $* *$ & $* *$ \\
HT & $* *$ & $*$ & $* *$ & $* *$ \\
NE & $* *$ & $* *$ & $* *$ & $*$ \\
PE & $* *$ & $* *$ & $* *$ & $* *$ \\
PET & $* *$ & $* *$ & $* *$ & $* *$ \\
NHI & $* *$ & $n s$ & $* *$ & $n s$ \\
CHI & $* *$ & $* *$ & $* *$ & $* *$ \\
LE & $* *$ & $* *$ & $* *$ & $* *$ \\
DEA & $* *$ & $* *$ & $* *$ & $* *$ \\
DEB & $* *$ & $* *$ & $* *$ & $* *$ \\
DEM & $* *$ & $* *$ & $* *$ & $* *$ \\
P5OC & $* *$ & $n s$ & $* *$ & $* *$ \\
LC & $* *$ & $* *$ & $* *$ & $*$ \\
AC & $* *$ & $n s$ & $* *$ & $* *$ \\
EC & $* *$ & $* *$ & $* *$ & $n$ \\
EC/LC & $* *$ & $* *$ & $* *$ & $\mathrm{~ns}$ \\
DEM/LC & $* *$ & $* *$ & $* *$ & $* *$ \\
\hline
\end{tabular}

Referencias. AES: altura hasta la inserción de la espiga distal; AT: altura total de la planta; AC: ancho de 10 cariopses; $\mathrm{CHI}$ : número de cariopses por hilera; DEA: diámetro de la espiga en el ápice; DEB: diámetro de la espiga en la base; DEB: diámetro de la espiga en la base; DEM: diámetro de la espiga en el punto medio; EC: espesor de 10 cariopses; HT: número total de hojas/ planta; LC: longitud de 10 cariopses; LE: longitud de la espiga; NE: número de espigas por planta; NHES: número de hojas a la espiga distal; NHI: número de hileras de granos/espiga; P50C: peso de 50 cariopses; PE: peso de la espiga distal; PET: peso total de espigas/planta; Índices: EC/LC; DEM/LE. * $p \leq 0,05 ;{ }^{* *} p \leq 0,01$; ns= no significativo $(p>0,05)$.

medias de la primera y segunda variable canónica para los efectos $v_{i}$ y $h_{i}$, respectivamente. Si se comparan la Figuras 3 y 4 se observan diferencias importantes en las relaciones entre las OTUs. En la Figura 3, Amarillo Ancho aparece aislada de las demás OTUs, mientras que en la Figura 4, Pororó Chico está más cercana de Amarillo Ancho y aislada de las demás OTUs. En los fenogramas (Figs. 5 y 6), se observa el grado de similitud entre las OTUs, sobre la base de los mismos efectos $\left(v_{i}\right.$ y $\left.h_{i}\right)$. Si se compara la distribución de las OTUs en el diagrama de dispersión (Fig. 3) con el fenograma (Fig. 5) se observa que existe una coincidencia casi total, distinguiéndose los siguientes grupos: $\mathbf{G}_{1}$ : formado por el núcleo (Pipoca Amarillo - Pororó Chico) y (Pororó Grande) más distante del par anterior; $\mathbf{G}_{2}$ : que incluye a Tupi Amarillo y Pipoca Colorado; y $\mathbf{G}_{3}$ representado por Amarillo Ancho, aislado de los dos grupos anteriores.

Mientras que en el fenograma de la Fig. 6, basado en los efectos de heterosis $\left(h_{i}\right)$ se observan relaciones genéticas diferentes de la Fig. 5, donde se distinguen los grupos: $\mathbf{G}_{1}$ : integrado por los núcleos: Pipoca Amarillo - Tupi Amarillo y Amarillo Ancho - Pipoca Colorado, G2: representado por la OTU Pororó Chico y G3 representada por la OTU Pororó Grande las que permanecen relativamente aisladas. Es decir que esta última clasificación basada en los efectos $h_{i}$ difiere de la clasificación basada en los efectos $v_{i}$. También se observan diferencias entre el gráfico de dispersión (Fig. 4) y el fenograma (Fig. 6), que pueden atribuirse a la distorsión que se produce en la representación gráfica bidimensional.

Cruzamientos recíprocos: En la Tabla 8, se observa el nivel de significancia de los componentes genéticos correspondiente a cada una de las variables para los cruzamientos recíprocos y directos. La heterosis media $\left(^{-}\right)$resultó, en ambos cruzamientos, no significativa para el número de hojas hasta la espiga superior, el peso de cincuenta cariopses y la anchura de los cariopses; mientras que el diámetro de la espiga en el ápice, es significativa para los cruzamientos directos y no significativa para los cruzamientos recíprocos y a la inversa número de hileras de granos/espiga , resultó no significativo en los cruzamientos directos y altamente significativo en los cruzamientos recíprocos. El número total de hojas por planta resultó significativo en los cruzamientos directos y recíprocos. Asimismo, para el resto de los caracteres los efectos de la heterosis media $(\bar{h})$ son altamente significativos para ambos tipos de cruzamientos. Los efectos de la variedad $\left(v_{i j}\right)$ y de la heterosis varietal $\left(h_{i j}\right)$ fueron todos altamente 
P. Melchiorre et al. - Relaciones fenotípicas y genéticas entre las razas de maíz nativas, Misiones

Tabla 6. Cruzamientos directos. Matriz de distancias genéticas entre poblaciones raciales para los efectos de la variedad (vij). ${ }^{*} p \leq 0,05 ;{ }^{* *} p \leq 0,01 ; n s=$ no significativo $(p>0,05)$

\begin{tabular}{|c|c|c|c|c|c|}
\hline & V6 (P14) & V5 (P13) & V4 (P12) & V3 (P11) & V2 (T) \\
\hline V1 (A) & $206,27^{\star *}$ & $221,84^{* *}$ & $191,57^{* *}$ & $148,78^{* *}$ & $145,66^{* *}$ \\
\hline V2 (T) & $137,59^{\star *}$ & $146,00^{* *}$ & $106,67^{\star \star}$ & $78,98^{* *}$ & \\
\hline V3 (P11) & $108,73^{\star *}$ & $104,22^{* *}$ & $79,15^{\star *}$ & & \\
\hline V4 (P12) & $93,18^{* *}$ & $75,20^{* *}$ & & & \\
\hline V5 (P13) & $79,93^{* *}$ & & & & \\
\hline
\end{tabular}

Tabla 7. Cruzamientos directos. Matriz de distancias genéticas entre poblaciones raciales para los efectos de la heterosis varietal $\left(h_{i j}\right)$.

\begin{tabular}{|c|c|c|c|c|c|}
\hline & h6 (P14) & h5 (P13) & h4 (P12) & h3 (P11) & h2 (T) \\
\hline h1 (A) & $43,37^{* *}$ & $50,48^{* *}$ & $39,18^{* *}$ & $37,08^{*}$ & $52,27^{\star *}$ \\
\hline h2 (T) & $59,65^{\star *}$ & $47,29^{* *}$ & $28,80(0)$ & $47,29^{\star *}$ & \\
\hline h3 (P11) & $43,15^{\star *}$ & $51,55^{\star *}$ & $33,00^{*}$ & & \\
\hline h4 (P12) & $43,17^{* *}$ & $44,14^{\star *}$ & & & \\
\hline h5 (P13) & $49,72^{*}$ & & & & \\
\hline
\end{tabular}

Referencias. A: Amarillo Ancho; P11: Pipoca Colorado; P12: Pipoca Amarillo; P13: Pororó Chico; P14: Pororó Grande; $\mathrm{T}$ : Tupi Amarillo. ${ }^{*} \mathrm{p} \leq 0,05 ;{ }^{* *} \mathrm{p} \leq 0,01$; ns $=$ no significativo $(\mathrm{p}>0,05)$.

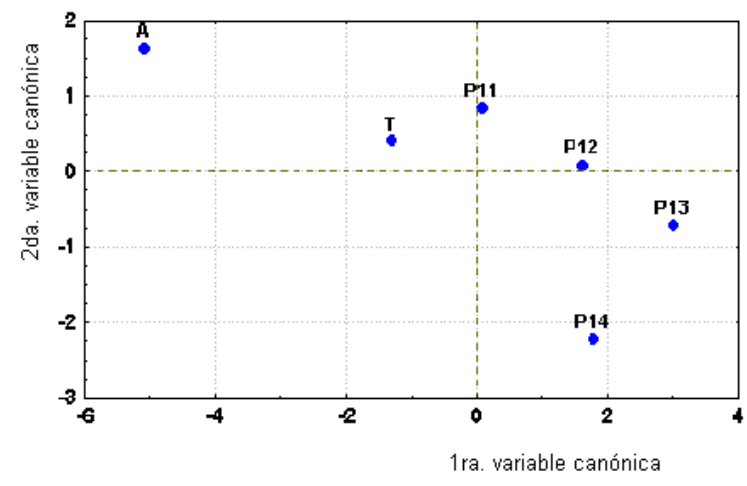

Fig. 3. Diagrama de dispersión de las razas parentales según valores medios de las dos primeras variables canónicas para los efectos de las variedades $\left(v_{i}\right)$. Abreviaturas: A: Amarillo Ancho; P11: Pipoca Colorado; P12: Pipoca Amarillo; P13: Pororó Chico; P14: Pororó Grande; T: Tupí Amarillo.

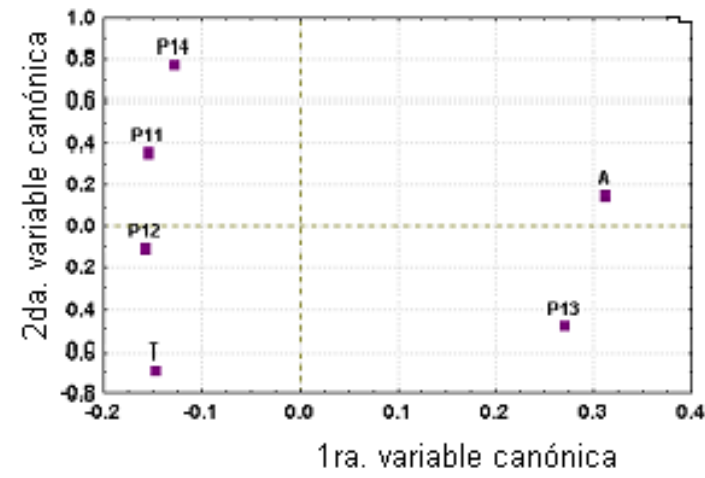

Fig. 4. Diagrama de dispersión de las razas parentales según valores medios de las dos primeras variables canónicas para los efectos de la heterosis $\left(h_{i}\right)$. Abreviaturas: A: Amarillo Ancho; P11: Pipoca Colorado; P12: Pipoca Amarillo; P13: Pororó Chico; P14: Pororó Grande; T: Tupí Amarillo. 


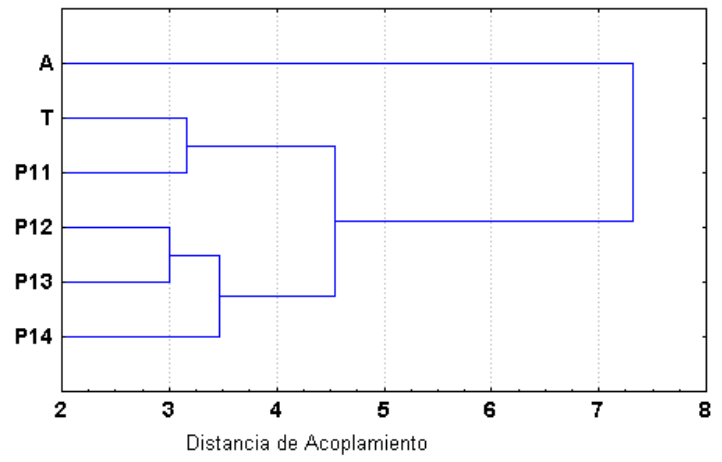

Fig. 5. Fenograma (UPGMA) obtenido a partir de la distancia euclidiana entre las razas parentales según valores medios de las 5 primeras variables canónicas para los efectos de las variedades $\left(v_{i}\right)$. Abreviaturas: A: Amarillo Ancho; P11: Pipoca Colorado; P12: Pipoca Amarillo; P13: Pororó Chico; P14: Pororó Grande; T: Tupí Amarillo.

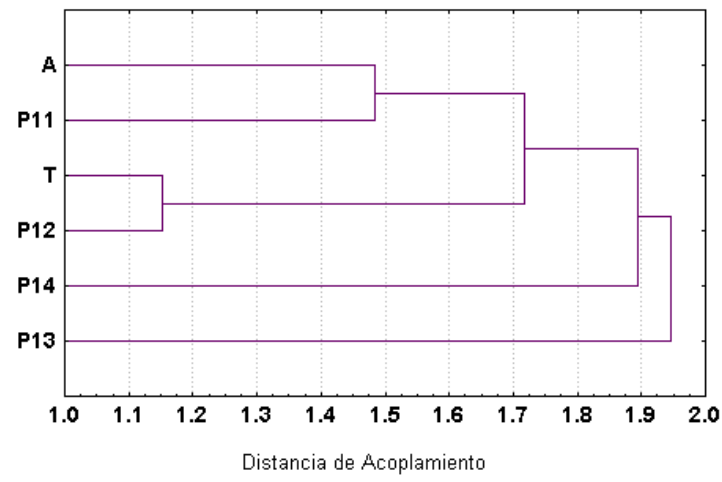

Fig. 6. Fenograma (UPGMA) obtenido a partir de la distancia euclidiana entre las razas parentales según valores medios de las 5 primeras variables canónicas para los efectos de la heterosis $\left(h_{i}\right)$ Abreviaturas: A: Amarillo Ancho; P11: Pipoca Colorado; P12: Pipoca Amarillo; P13: Pororó Chico; P1: Pororó Grande; T: Tupí Amarillo.

Tabla 8. Comparación de los cruzamientos directos $(\mathrm{CD})$ y recíprocos $(\mathrm{CR})$ de las poblaciones. Niveles de significancia de las componentes genéticas.

\begin{tabular}{|c|c|c|c|c|c|c|c|c|}
\hline \multirow[t]{2}{*}{ Caracteres } & \multicolumn{2}{|c|}{$\begin{array}{l}\text { Efectos de la } \\
\text { Variedad (vij) }\end{array}$} & \multicolumn{2}{|c|}{$\begin{array}{c}\text { Efectos de heterosis } \\
\text { media (h) }\end{array}$} & \multicolumn{2}{|c|}{$\begin{array}{c}\text { Efectos de heterosis } \\
\text { varietal (hij) }\end{array}$} & \multicolumn{2}{|c|}{$\begin{array}{c}\text { Efectos de heterosis } \\
\text { epecífica (hij) }\end{array}$} \\
\hline & CD & CR & CD & CR & CD & CR & CD & CR \\
\hline AES & $* *$ & $* *$ & $* *$ & ** & $* *$ & ** & $* *$ & ** \\
\hline NHES & $* *$ & $* *$ & ns & ns & $* *$ & ** & $* *$ & ** \\
\hline AT & $* *$ & $* *$ & $* *$ & $* *$ & $* *$ & ** & $* *$ & ** \\
\hline HT & $* *$ & $* *$ & * & * & $* *$ & ** & $* *$ & ** \\
\hline NE & $* *$ & * & $* *$ & ** & $* *$ & ** & * & ** \\
\hline PE & $* *$ & $* *$ & $* *$ & ** & $* *$ & $* *$ & $* *$ & $* *$ \\
\hline PET & $* *$ & $* *$ & $* *$ & ** & $* *$ & ** & $* *$ & $* *$ \\
\hline NHI & $* *$ & $* *$ & ns & $* *$ & $* *$ & $* *$ & ns & ns \\
\hline $\mathrm{CHI}$ & $* *$ & ns & $* *$ & ** & $* *$ & ns & $* *$ & ** \\
\hline LE & $* *$ & ** & $* *$ & $* *$ & $* *$ & $* *$ & ** & $* *$ \\
\hline DEA & $* *$ & ** & $* *$ & ns & $* *$ & ** & $* *$ & * \\
\hline DEB & $* *$ & $* *$ & $\star \star *$ & $* *$ & $* *$ & $* *$ & $* *$ & $* *$ \\
\hline DEM & $* *$ & $* *$ & $* *$ & $* *$ & $* *$ & $* *$ & $* *$ & * \\
\hline P50C & $* *$ & ** & ns & ns & $* *$ & $* *$ & $* *$ & ns \\
\hline LC & $* *$ & ** & $* *$ & ** & $\star *$ & $* *$ & * & ** \\
\hline$A C$ & $* *$ & $* *$ & ns & ns & $* *$ & $* *$ & $* *$ & ns \\
\hline EC & ** & ** & $* *$ & ** & $* *$ & $* *$ & ns & $* *$ \\
\hline EC/LC & $* *$ & $* *$ & $* *$ & ** & $* *$ & ns & ns & ** \\
\hline DEM/LC & ** & $* *$ & ** & ** & $* *$ & $* *$ & ** & $* *$ \\
\hline
\end{tabular}

Referencias. AES: altura hasta la inserción de la espiga distal; AC: ancho de 10 cariopses; AT: altura total de la planta; $\mathrm{CHI}$ : número de cariopses por hilera; DEA: diámetro de la espiga en el ápice; DEB: diámetro de la espiga en la base; DME: diámetro de la espiga en el punto medio; EC: espesor de 10 cariopses; HT: número total de hojas/planta; LC: longitud de 10 cariopses; LE: longitud de la espiga; NE: número de espigas por planta; NHES: número de hojas a la espiga distal; NHI: número de hileras de granos/espiga; P50C: peso de 50 cariopses; PE: peso de la espiga distal; PET: peso total de espigas/planta; Índices: EC/LC y DME/LE. ${ }^{*} p \leq 0,05 ;{ }^{* *} p \leq 0,01$; ns= no significativo $(p>0,05)$. 


\section{P. Melchiorre et al. - Relaciones fenotípicas y genéticas entre las razas de maíz nativas, Misiones}

significativos exceptuando al número de granos por hilera y el índice EC/LC, para los cruzamientos recíprocos. Los efectos de la heterosis específica $\left(h_{i j}\right)$, en los cruzamientos directos fueron todos altamente significativos, exceptuando las variables número de hileras de granos/espiga, espesor de 10 cariopses y el índice EC/LC, mientras que en los cruzamientos recíprocos resultaron no significativos el número de hileras de granos/espiga, el peso de cincuenta cariopses y anchura de los cariopses. Los valores de distancias genéticas (Tabla 9) entre poblaciones para los efectos $v_{i}$ varían entre 65,18 y 185,00 , siendo son todos altamente significativos. El valor más alto de distancia se registró entre Amarillo Ancho y Pororó Chico, siendo similar a los cruzamientos directos, mientras el valor más pequeño correspondió al par Pipoca Amarillo y Pororó Chico, siendo diferente a los cruzamientos directos. Los valores de distancias genéticas (Tabla 10) entre poblaciones para los efectos $h_{i}$ varían entre 30,52 y 68,83 y son todos altamente significativos, excepto en el par Tupí Amarillo Pororó Chico. El valor más alto correspondió al par Amarillo Ancho - Pipoca Amarillo y el valor menor al par Pipoca Colorado - Pororó Chico, no coincidentes con los cruzamientos directos. En los diagramas de dispersión (Figs. 7 y 8) se representan las poblaciones parentales según las medias de la primera y segunda variable canónica para los efectos $v_{i}$ y $h_{i}$, respectivamente. Si se comparan ambas figuras se observan diferencias importantes en las relaciones entre las OTUs: en la Figura 7, Amarillo Ancho aparece aislada de las demás OTUs, mientras que en la Figura 8, Tupi Amarillo es la que aparece más aislada de las demás OTUs. En los fenogramas de las Figuras 9 y 10, se observan semejanzas entre los dos grupos formados a un bajo nivel de similitud, mientras que se notan algunas diferencias en el resto. Si se compara la distribución de las

Tabla 9. Cruzamientos recíprocos. Matriz de distancias genéticas entre poblaciones raciales para los efectos de la variedad ( $\mathrm{Vij})$.

\begin{tabular}{|c|c|c|c|c|c|}
\hline & $v_{6}(P 14)$ & $v_{5}(P 13)$ & $v_{4}(P 12)$ & $v_{3}(P 11)$ & $\mathbf{v}_{2}(T)$ \\
\hline$v_{1}(\mathrm{~A})$ & $172,38^{\star *}$ & $185,00^{* *}$ & $165,67^{* *}$ & $124,69^{\star *}$ & $126,27^{* *}$ \\
\hline$v_{2}(\mathrm{~T})$ & $116,42^{* *}$ & $124,47^{* *}$ & $94,37^{* *}$ & $75,96^{* *}$ & \\
\hline$v_{3}(\mathrm{P} 11)$ & $88,93^{* *}$ & $87,37^{\star *}$ & $68,91^{\star *}$ & & \\
\hline$v_{4}(\mathrm{P} 12)$ & $81,10^{\star *}$ & $65,18^{* *}$ & & & \\
\hline$v_{5}(\mathrm{P} 13)$ & $68,04^{* *}$ & & & & \\
\hline
\end{tabular}

Referencias. A: Amarillo Ancho; P11: Pipoca Colorado; P12: Pipoca Amarillo; P13: Pororó Chico; P14: Pororó Grande; $\mathrm{T}$ : Tupi Amarillo. ${ }^{*} \mathrm{p} \leq 0,05 ;{ }^{* *} \mathrm{p} \leq 0,01$; ns= no significativo $(\mathrm{p}>0,05)$.

Tabla 10. Cruzamientos recíprocos. Matriz de distancias genéticas entre poblaciones raciales para los efectos de la heterosis $\left(h_{i}\right)$.

\begin{tabular}{|c|c|c|c|c|c|}
\hline & $h_{6}(\mathrm{P} 14)$ & $h_{5}(\mathrm{P} 13)$ & $h_{4}$ (P12) & $h_{3}(\mathrm{P} 11)$ & $h_{2}(\mathrm{~T})$ \\
\hline$h_{1}(\mathrm{~A})$ & $50,06^{* *}$ & $50,29^{\star *}$ & $68,83^{\star *}$ & $48,57^{\star *}$ & $55,71^{* *}$ \\
\hline$h_{2}(\mathrm{~T})$ & $47,15^{\star *}$ & $39,00^{*}$ & $39,08^{* *}$ & $37,13^{\star *}$ & \\
\hline$h_{3}(\mathrm{P} 11)$ & $39,84^{\star *}$ & $30,52^{* *}$ & $38,19^{* *}$ & & \\
\hline$h_{4}(\mathrm{P} 12)$ & $57,32^{\star *}$ & $46,62^{\star *}$ & & & \\
\hline$h_{5}$ (P13) & $39,14^{* *}$ & & & & \\
\hline
\end{tabular}

Referencias. A: Amarillo Ancho; P11: Pipoca Colorado; P12: Pipoca Amarillo; P13: Pororó Chico; P14: Pororó Grande; $\mathrm{T}$ : Tupi Amarillo. ${ }^{*} \mathrm{p} \leq 0,05 ;{ }^{* *} \mathrm{p} \leq 0,01 ; \mathrm{ns}=$ no significativo $(\mathrm{p}>0,05) ; h_{i j}$ : efectos de la heterosis varietal. 


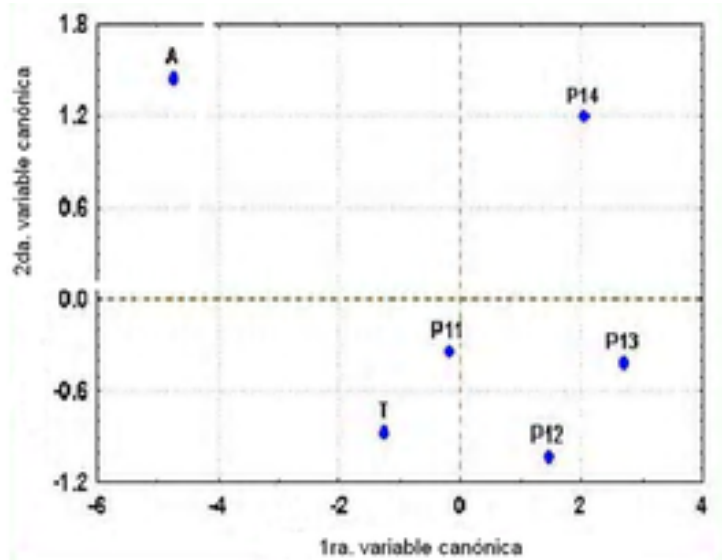

Fig. 7. Medias de la primera y segunda variable canónica de las poblaciones parentales para los efectos de las variedades $\left(v_{i}\right)$ Abreviaturas: A: Amarillo Ancho; P11: Pipoca Colorado; P12: Pipoca Amarillo; P13: Pororó Chico, P14: Pororó Grande; T: Tupí Amarillo.

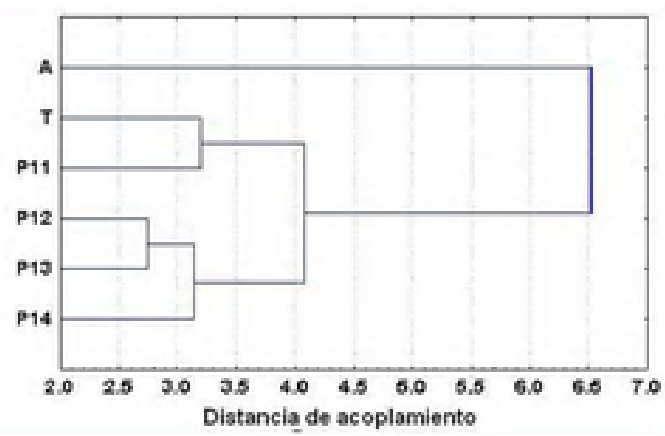

Fig. 9. Fenograma (UPGMA) obtenido a partir de la distancia euclidiana entre las razas parentales según valores medios de las 5 primeras variables canónicas para los efectos de las variedades $\left(v_{i}\right)$ Abreviaturas: A: Amarillo Ancho; P11: Pipoca Colorado; P12: Pipoca Amarillo; P13: Pororó Chico; P14: Pororó Grande; T: Tupí Amarillo.

OTUs en el diagrama de dispersión (Fig. 7) con el fenograma (Fig. 9) se observa que existe casi una total coincidencia en cuanto a las relaciones entre las OTUs, distinguiéndose tres grupos (G1, G2 y G3). $\mathbf{G}_{1}$ : formados por el núcleo Pipoca Amarillo - Pororó

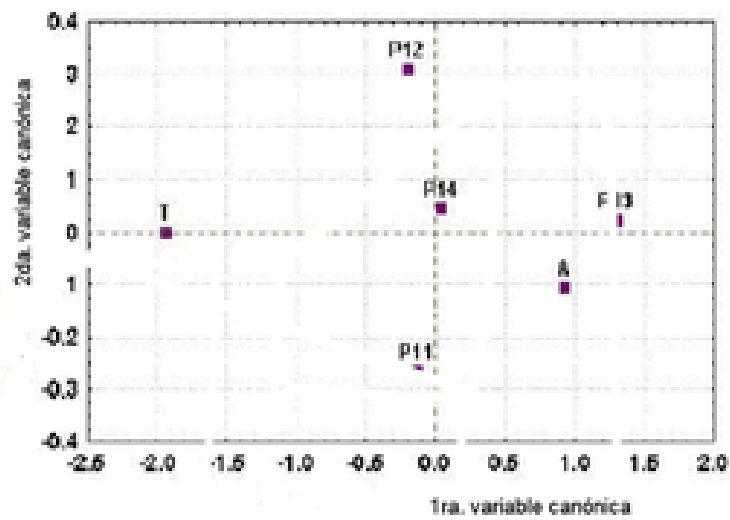

Fig. 8. Medias de la primera y segunda variable canónica de las poblaciones parentales para los efectos de la heterosis $\left(h_{i}\right)$ Abreviaturas: A: Amarillo Ancho; P11: Pipoca Colorado; P12: Pipoca Amarillo; P13: Pororó Chico; P14: Pororó Grande; T: Tupí Amarillo.

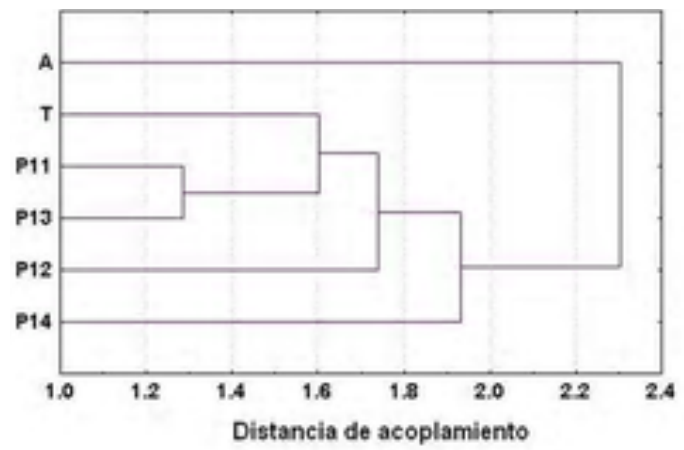

Fig. 10. Fenograma (UPGMA) obtenido a partir de la de distancia euclidiana entre las razas parentales según valores medios de las 5 primeras variables canónicas para los de la heterosis $\left(h_{\mathrm{i}}\right)$ Abreviaturas: A: Amarillo Ancho; P11: Pipoca Colorado; P12: Pipoca Amarillo; P13: Pororó Chico; P14: Pororó Grande; T: Tupí Amarillo.

Chico y Pororó Grande, siendo Pororó Grande el más distante del anterior par de OTUs; $\mathbf{G}_{2}$ : que incluye a Tupi Amarillo y Pipoca Colorado y $\mathbf{G}_{3}$ : representado por Amarillo Ancho, aislado de los dos grupos anteriores. 


\section{P. Melchiorre et al. - Relaciones fenotípicas y genéticas entre las razas de maíz nativas, Misiones}

Relaciones genéticas algo diferentes, basadas en los efectos de heterosis $\left(h_{i}\right)$, se observan en el fenograma de la Fig. 10 donde el $\mathbf{G}_{1}$, estaría representado por Pororó Grande, $\mathbf{G}_{\mathbf{2}}$ por el núcleo Pipoca Colorado - Pororó Chico, Pipoca Amarillo y Tupi Amarillo, y $\mathbf{G}_{3}$, por Amarillo Ancho. También se observan diferencias entre el gráfico de dispersión (Fig. 8) y el fenograma (Fig. 10), que podrían deberse a la distorsión originada por el método de representación, dado que el fenograma está basado en las $5 \mathrm{VC}$ a diferencia del diagrama de dispersión en el que se representa a las OTU según las dos primeras VC.

El reagrupamiento de las OTUs, basado en los efectos $v_{i}$ (Fig. 9) presenta total concordancia con el reagrupamiento de los cruzamientos directos (Fig. 5), mientras que se observan diferencias en el reagrupamiento de las OTUs, basadas en los efectos $h_{i}$ (Figs. 6 y 10).

\section{Discusión y Conclusiones}

Los resultados del ANVA, confirmaron la existencia de una elevada variabilidad morfológica y genética en las formas raciales de maíz nativas del Noreste de Argentina (Misiones) estudiadas, con diferencias altamente significativas, para casi todas las variables consideradas. Asimismo los coeficientes de variación sugieren, en general, que existe una variación menor en los caracteres de la espiga y de los granos en comparación con los caracteres vegetativos. Ello indicaría que los datos referidos a los caracteres de la espiga y del grano tienen una mayor homogeneidad y/o que la media aritmética es más representativa que aquellos referidos a los caracteres vegetativos (Sotello, 1983). Asimismo los resultados del ANVA realizado para la comparación de las medias correspondientes a los datos obtenidos en el Jardín Botánico (Buenos Aires) y en Ruiz de Montoya (Misiones), indican, en general, que existen diferencias significativas entre sitios de cultivo y entre genotipos, como así también interacción genotipo por ambiente $(\mathrm{G} \times$ S). Esta última, puede atribuirse a los diferentes factores que afectan el crecimiento y el desarrollo de una planta. Entre esos factores se encuentran efectos predecibles: edáficos (química y física del suelo), climatológicos, (radiación solar y hora luz) y los efectos no predecibles: climatológicos (lluvias, humedad relativa del aire y, temperatura) y biológicos (insectos, enfermedades, agentes simbióticos y micorrizas) que son muy diferentes en cada uno de los sitios de cultivo. En general, en los maíces de clima cálido el tallo casi no manifiesta innovaciones basales (macollos) y en los de clima frío, el número de macollos es variable, siendo varias las causas que afectan la distribución de este carácter, como la variedad o la raza, la precocidad, el ambiente, la altitud y la tecnología del cultivo (densidad, fertilidad, humedad, etc.) (Reyes Castañeda, 1990).

Los resultados obtenidos del ADC indican que las dos primeras variables canónicas permiten explicar la variación encontrada y poder representarla en un gráfico bidimensional, dado que sintetizan un porcentaje importante de las diferencias observadas entre las poblaciones raciales estudiadas $(67 \%$ de la variación total). Además, se pudo observar que casi todas las progenies de los cruzamientos tienen en general un comportamiento superior a sus progenitores, en cuanto a los caracteres de maíz nativas del Noreste de Argentina (Misiones), altura hasta la inserción de la espiga distal, longitud de la espiga y número de cariopses por hilera. Ello indicaría un grado menor de afinidad entre los respectivos progenitores que aquellas progenies que se ubican dentro del rango de variación de sus progenitores. Por lo general, se espera que las combinaciones híbridas ("F") se sitúen a mitad de camino de los dos progenitores, cuando esto no ocurre, podría atribuirse a la existencia de efectos genéticos no aditivos para los caracteres considerados. En relación a las poblaciones comerciales utilizadas como testigos, se evidencia que las mismas superan al resto de los genotipos parentales y/o de los cruzamientos inclusive, en cuanto a los caracteres asociados a las dos primeras $\mathrm{VC}$.

Los resultados del análisis de agrupamiento fenotípico, al nivel más bajo de similitud, permiten distinguir dos grupos:

Grupo $1\left(\mathrm{G}_{1}\right)$ : está compuesto por los dos híbridos comerciales (TH1 y TH2), utilizados como testigos; como era de esperarse, éstos están estrechamente relacionados entre sí y diferenciados de las OTUs restantes.

Grupo $2\left(\mathrm{G}_{2}\right)$ : es más amplio y heterogéneo y comprende a las seis poblaciones parentales y la 
progenie de 15 cruzamientos. Se diferencia a su vez en los subgrupos: SA y SB:

Subgrupo A: está integrado por la raza Amarillo Ancho y por los cruzamientos Tupí Amarillo $\times$ Amarillo Ancho y Pipoca Colorado $\times$ Amarillo Ancho.

Subgrupo B. Se divide en dos Conjuntos: C1 y C2

C1: está representado por Pororó Grande.

$\mathrm{C} 2$ : se diferencia a su vez en dos sub-conjuntos: $\mathrm{C} 2 \mathrm{a}$ y $\mathrm{C} 2 \mathrm{~b}$

Sub-conjunto C2a: constituido por Tupí Amarillo, relativamente aislado de los demás OTUs y los núcleos (Pipoca Colorado - Pororó Chico $\times$ Amarillo Ancho), (Pipoca Amarillo $\times$ Amarillo Ancho - Pipoca Colorado $\times$ Tupi Amarillo), Pororó Grande $\times$ Amarillo Ancho, Pipoca Amarillo $\times$ Tupí Amarillo - Pororó Grande $\times$ Tupí Amarillo).

Sub-conjunto $\mathrm{C} 2 \mathrm{~b}$ : se divide a su vez en otros tres sub-conjuntos: b1, b2 y b3

b1: formado por Pipoca Amarillo y la progenie de los cruzamientos Pipoca Amarillo $\times$ Pipoca Colorado, Pororó Chico $\times$ Pipoca Amarillo.

b2: está compuesto por la progenie de los cruzamientos Pororó Chico $\times$ Tupi, Pororó Grande $\times$ Pororó Chico, Pororó Chico $\times$ Pipoca Colorado, Pororó Grande $\times$ Pipoca Colorado, y Pororó Grande $\times$ Pipoca Amarillo.

b3: está representado por Pororó Chico.

\section{Análisis genético}

El análisis genético de una población tiene como objetivo poner en evidencia la importancia relativa de los factores genéticos y ambientales en la determinación de las diferencias entre individuos. Sobre la base de esta información, es posible hacer previsiones acerca de la transmisibilidad de las características individuales a las progenies. La componente genética expresa, principalmente, el efecto de la variedad que comprende, además de la componente genética aditiva, una cuota de efectos debido a la dominancia y a la interacción entre loci (epistasis). Asimismo, la manifestación del grado de heterosis en las progenies, depende del grado de endogamia de los padres. Lo más frecuente es que, en cruzamientos entre fenotipos con gran diversidad genética (frecuencias génicas distintas) muestren una " $F_{1}$ " con alta heterosis, mientras que cuando se cruzan poblaciones relativamente similares y adaptadas a condiciones ecológicas semejantes, se espera, por lo general, un bajo grado de heterosis (Hiorth, 1985). Es decir, en general, se espera que la respuesta heterótica aumente con el aumento de la divergencia genética de los padres (Moll et al., 1965). Sin embargo, la relación no es completamente linear y una carencia de heterosis es posible aún con poblaciones muy diferentes (Cress, 1966). En este trabajo, la progenie de todos los cruzamientos presentaron diferente grado de heterosis, exceptuando a los cruzamientos (Pipoca Colorado $\times$ Tupí Amarillo) y (Pororó Chico $\times$ Tupí Amarillo). Asimismo, la progenie de los cruzamientos (Tupí Amarillo $\times$ Amarillo Ancho $)$ y $(\mathrm{P} 14 \times$ Pipoca Colorado $)$ expresaron los valores promedios más altos y más próximos a los promedios de las dos variedades comerciales utilizadas como testigos. Los resultados de estos cruzamientos no son coincidentes con las mayores distancias genéticas entre las poblaciones parentales, registradas para los efectos $v_{i}$ o $h_{i}$, posiblemente debido a variaciones transgresivas.

Las relaciones genéticas observadas fueron diferentes según el parámetro genético que se considerara para el reagrupamiento. Así, por ejemplo, la clasificación basada en los efectos $h_{i}$ difiere de la clasificación basada en los efectos $v_{i}$.

Los cruzamientos recíprocos, en el análisis genético, por lo general, no son considerados porque dan descendencias iguales o equivalentes a los cruzamientos directos (Hiorth, 1985).

En este grupo de maíces, donde se analizaron por separado, también los efectos recíprocos, el reagrupamiento de las OTUs, basado en los efectos $v_{i}$, presentan total concordancia con el reagrupamiento de los cruzamientos directos (ver los gráficos de dispersión y fenogramas correspondientes), mientras que se observaron diferencias en el reagrupamiento de las OTUs basado en los efectos $h_{i}$.

Los resultados obtenidos son importantes desde el punto de vista taxonómico y evolutivo. Además, pueden contribuir a la selección adecuada de progenitores a incluirse en los programas de mejoramiento, previa evaluación de las posibles interacciones genotipo-ambiente (Reyes Castañeda, 1990). Finalmente, la síntesis de la información relevante de las formas raciales en estudio, en función de los caracteres cuantitativos empleados, puede, constituir el punto de partida para ulteriores investigaciones. 


\section{P. Melchiorre et al. - Relaciones fenotípicas y genéticas entre las razas de maíz nativas, Misiones}

\section{Contribución de los AUtORES}

$\mathrm{JCH}$ : proporcionó las muestras del material original para el estudio y realizó lectura crítica del manuscrito. NB: realizó el procesamiento de los datos incluido las figuras y las tablas correspondientes y lectura crítica del manuscrito. PM: diseño y realización de la investigación, recolección de datos (a campo y de laboratorio), análisis e interpretación de los resultados. Redacción del manuscrito y adecuaciones necesarias en las tablas y figuras.

\section{Agradecimientos}

A la Dra. Mariana Mampaey por su cooperación y por el ofrecimiento del sitio para realizar el ensayo, a los Sres. Juan Baecke y José Luis Baecke y Señora, por la colaboración prestada en las tareas técnicas de siembra, relevamiento de datos a campo y obtención de las muestras en espigas del cultivo. Asimismo agradecemos, a la Universidad de Buenos Aires (Proyecto UBACyT, 01/G806, Dir. Daniel Roberto Tortosa) y al FONCyT (Proyecto PICTR 2002-00109, Dir. Julián Cámara Hernández) por los subsidios otorgados para financiar este trabajo; al Dr. Jorge Casal, Dra. Florencia Realini y a la Ing. Agr. Ana M. Miante Alzogaray por las sugerencias y lectura critica del manuscrito.

\section{Bibliografía}

ABIUSSO, A. \& J. CÁMARA HERNÁNDEZ. 1974. Los maíces autóctonos de la Quebrada de Humahuaca (Jujuy, Argentina). Revista Fac. Agron. 50: 1-25.

BIANCHI, A. \& F. SALAMINI. 1973. Il mais, Quaderno II (59 págs), in Trattato di Genetica Agraria Speciale, Edagricole.

BRACCO, M. 2008. Variabilidad microsatelite en maíces reventadores autóctonos. Tesis de Licenciatura. Facultad de Ciencias Exactas y Naturales Universidad de Buenos Aires. 141.

BRACCO, M. 2012. Caracterización genética del germoplasma de razas de maíz autóctonas provenientes del noreste argentino. Tesis Doctoral. Facultad de Ciencias Exactas y Naturales Universidad de Buenos Aires.
BRACCO, M., V. LIA, A. M. GOTTLIEB, J. CÁMARA HERNÁNDEZ \& L. POGGIO. 2008. Genetic diversity in maize landraces from indigenous settlements of Northeastern Argentina. Genetica 135: 39-49.

BRACCO, M., V. LIA, J. CÁMARA HERNÁNDEZ, L. POGGIO, A. M. GOTTLIEB. 2012. Genetic diversity of maize landraces from lowland and highland agroecosystems of Southern South America: implications for the conservation of native resources. Ann. Appl. Biol. 160: 308-321.

BRACCO M., J. CASCALES, J. CÁMARA HERNÁNDEZ, L. POGGIO, A. M. GOTTIEB \& V. LIA. 2016. Dissecting maize diversity in lowland South America: genetic structure and geographic distribution models. BMC Plant Biology 16: 186. https://doi. org/10.1186/s12870-016-0874-5.

BRIEGER, F. G., J. T. A.GURGEL, E. PATERNIANI, A. BLUMENSCHEIN \& M. R. ALLEONI. 1958. Races of maize in Brazil and other eastern South American countries. Nat. Acad. Sci. Nat. Res. Council. Publ. 593. Washington.

CÁMARA HERNÁNDEZ, J. \& A. M. MIANTE ALZOGARAY. 1979. Las razas de maíz de la provincia de Salta. Resúmenes XVII Jorn. Arg. de Botánica, Santa Rosa, Argentina.

CÁMARA HERNÁNDEZ, J. \& A. M. MIANTE ALZOGARAY. 1981. Razas de maíz (Zea mays L.) nativas de Tucumán y Catamarca. Resúmenes XVIII Jorn. Arg. de Botánica. Tucumán, Argentina.

CÁMARA HERNÁNDEZ, J. \& A. M. MIANTE ALZOGARAY. 2003. Caracterización y clasificación, en razas, de maíces nativos de la provincia de Misiones. Argentina. Libro de resúmenes IV Simposio de recursos genéticos para América latina y el Caribe. Mar de Plata, Argentina.

CÁMARA HERNÁNDEZ, J., A. M. MIANTE ALZOGARAY, R. BELLÓN \& A. J. GALMARINI. 2012. Razas de maíz nativas de la Argentina. Editorial Facultad de Agronomía UBA.

CAMUSSI, A. \& E. OTTAVIANO. 1979. Uso degli effetti genetici di caratteri metrici a scopo tassonomico. Quaderni di epidemiologia (supp. 1). De Bona, Milano.

CAMUSSI, A., P. L. SPAGNOLETTI ZEULI \& P. MELCHIORRE. 1983. Numerical taxonomy of Italian maize populations: genetic distances on the basis of heterotic effects. Maydica 28: 411-424.

CAMUSSI, A., E. OTTAVIANO, T. CALINSKI \& Z. KACZMAREK. 1985. Genetic distances based on quantitative traits. Genetics 111: 945-962. 
CATÁlOGO INTA. 1997. Catálogo de Germoplasma de maíz. Argentina. Biblioteca Agraria Tropicale. Instituto Agronomico per L'Oltramare. Firenze.

CRESS, C. E. 1966. Heterosis of the hybrid related to gene frequency differences between two populations. Genetics 53: 269-274.

EYHERABIDE, G. H. 2004. Incorporación de germoplasma indígena de maíz en materiales elite. Revista IDIA 21: 105-110.

FALCONER, D. S. \& T. MACKAY. 1996. Introduction to quantitative genetics (2nd ed.) Longman, London.

FRAYSSINET, N, S. CARDONE, I. FURLAN, N. BARTOLONI \& C. BANCHERO. 2001. Genic male sterility in native maize populations. J. Basic \& Appl Genetics 14: 25-31.

FOURASTIÉ, M. F. 2010. Caracterización de razas nativas de maíz del Noroeste argentino mediante citogenética clásica y molecular (FISH). Tesis de Licenciatura. Facultad de Ciencias Exactas y Naturales, UBA. Argentina.

FOURASTIÉ, M. F. 2015. Estudios citogenéticos en razas de maíz del NOA: Caracterización cariotípica, evaluación del tamaño del genoma y frecuencia de cromosomas B. Tesis doctoral de la UBA. Argentina.

FOURAstie, M. F., A. M. GOTTIEB, L. POGGIO \& G. E. GONZALEZ. 2017. Are cytological parameters of maize landraces (Zea mays ssp. mays) adapted along and altitudinal cline?. J. Plant Res. 131: 285296. https://doi. org/10.1007/s10265-017- 0996-3.

GARDNER, C. O. \& S. A. EBERHARDT. 1966. Analysis and interpretation of the variety cross diallel and related populations. Biometrics 22: 439-452.

GIROLA, C. D. 1919. Variedades de maíz cultivadas en Argentina. Talleres Gráficos J. Weiss y Preusche. Buenos Aires. Argentina.

GRIFFING, B. 1956. Concept of general and specific combining ability in relation to diallel crossing system. Aust. J. Bioi. Sci. 9: 463-493.

HIORTH, G. E. 1985. Genética Cuantitativa. I: Fundamentos Biológicos. Universidad Nacional de Córdoba, Facultad de Ciencias Agropecuarias. Córdoba, Argentina.

HOROVITZ, S. 1935. Distribución geográfica de factores genéticos en maíces autóctonos del norte argentino. Rev. Arg. Agr. 2: 133-135.

HOURQUESCOS, M. J., G. H. EYHERABIDE \& M. E. FERRER. 2003. Utilización de poblaciones locales en premejoramiento de maíz Libro de resúmenes $I V$ Simposio de recursos genéticos para América latina y el Caribe. Mar de Plata. Argentina.
LÍA, V. 2004. Diversidad genética y estructura poblacional en razas nativas de maíz (Zea mays ssp. mays) del Noroeste Argentino: presente y pasado del germoplasma autóctono. Tesis Doctoral. Laboratorio de Genética. Depto. de Ecología, Genética y Evolución UBA. Argentina.

LUNA, J. T., W. F. KUGLER, E. F. GODOY \& L. E. MAZZONI. 1964. Maíz (Zea mays L.) en PARODI, L. Enciclopedia Argentina de Agricultura $y$ Jardinería Vol. II. ACME, Buenos Aires. Argentina.

MELCHIORRE, P. 1992. Phenetic relationships among different races of maize (Zea mays ssp. mays) from Salta (Argentina). Maydica 37: 329-338.

MELCHIORRE, P., N. BARTOLONI, \& J. CÁMARA HERNÁNDEZ. 2006. Phenetic relationships among native races of maize (Zea mays ssp. mays) from North-eastern Argentina (Misiones). J. Genet. \& Breed. 60: 173-182.

MELCHIORRE, P., N. BARTOLONI \& J. CÁMARA HERNÁNDEZ. 2017. Relaciones fenéticas entre razas de maíz (Zea mays ssp. mays) nativas de la provincia de Jujuy (Argentina). Bol. Soc. Argent. Bot. 52: 717-735.

MIANTE ALZOGARAY, A. M., A. J. GALMARINI \& J. CÁMARA HERNÁNDEZ. 1996. Razas de maíz (Zea mays ssp. mays) nativas de Catamarca (Argentina). Resúmenes XXV Jorn. Arg. de Botánica, Mendoza.

MOLL, R. H., J. H. LONQUIST, J. VELEZ FORTUNO \& E. C. JOHNSON. 1965. The relationship of heterosis and genetic divergence in maize. Genetics 52: 139144.

OTTAVIANO, E. \& A. CAMUSSI. 1981. Phenotypic and genetic relationships between yield components in maize. Euphytica 30: 601-9.

PARODI, L. R. 1935. Relaciones de la agricultura prehispánica con la agricultura actual. Argentina actual. An. Acad. Nac. Agr. y Vet. 1: 115-168. Buenos Aires.

PARODI, L. R. 1947. Los maíces indígenas de la república argentina. Anales. Acad. Nac. Ci. Exact. Buenos Aires. XII: 9-14.

PARODI, L. R. 1966. La agricultura aborigen argentina. EUDEBA. Argentina.

POGGIO L., M. ROSATO, A.M. CHIAVARINO \& C.A. NARANJO. 1998. Genome size and environmental correlations in maize (Zea mays ssp. mays, Poaceae). Ann. Bot. 82: 107-115.

REALINI, M. F. 2017. Variabilidad citogenética de los maíces guaraníes del Noreste de Argentina: Caracterización cariotípica, tamaño del genoma 


\section{P. Melchiorre et al. - Relaciones fenotípicas y genéticas entre las razas de maíz nativas, Misiones}

y correlatos fenotípicos. Tesis Doctoral. Facultad de Ciencias Exactas y Naturales-Universidad de Buenos Aires. Argentina.

REALINI, M. F., L. POGGIO, J. CÁMARA HERNÁNDEZ, G. E. GONZÁLEZ. 2016. Intraspecific variation in genome size in maize: cytological and phenotypic correlates. $A o B$ PLANTS 8: plv138.

https://doi. org/10.1093/aobpla/plv138

REALINI, M. F., L. POGGIO, J. CÁMARA HERNÁNDEZ, G. E. GONZÁLEZ. 2018. Exploring karyotype diversity of Argentinian Guaranı maize landraces. Relationship among South American maize. PLoS ONE 13(6) e 0198398.

http://doi.org/10.1371/journal.pone.019839

REYES CASTAÑEDA, P. 1990. El maíz y su cultivo. México, D.F. A.G.T. Editor S.A.

ROBUTTI, J. L., F. S. BORRÁS, M. E. FERRER \& A. BIETZ. 2000. Grouping and Identification of Argentine Maize Races by Principal Component Analysis of Zein Reversrd-Phase HPLC Data. Cereal Chem. 77: 91-95.
RODRÍGUEZ, A., J. ROMERO, G. AVILA \& A. BRANDOLINI. 1968. Maíces bolivianos. FAO. Rome, Italy.

ROHLF, F. J. 1993. NTSYS (Numerical Taxonomy and Multivariate Analysis) System). Version 1.80. Exeter software. New York.

ROSATO, M., A. M. CHIAVARINO, C. A. NARANJO, J. CÁMARA HERNÁNDEZ \& L. POGGIO. 1998. Genome size and numerical polymorphism for the B chromosome in races of maize (Zea mays ssp. mays, Poaceae). Am. J. Bot. 85:168-174.

SOTELLO, M. G. 1983. Estadística. 3 C. Editores, Buenos Aires.

SNEATH, P. H. A. \& R. R. SOKAL. 1973. Numerical Taxonomy. The principles and practice of numerical classification. Freeman and Co., San Francisco. USA.

TORREGROSA, M., J. CÁMARA HERNÁNDEZ, L. SOLARI, J. SAFONT LIS \& O. CAVALLIERI. 1980. Clasificación preliminar de las formas raciales de maíz y su distribución geográfica en la República Argentina. Asoc. Ing. Agr. Zona Norte Prov. Buenos Aires. II Congreso Nacional de Maíz 7: 5-17. 
